\title{
基于分子印迹与表面增强拉曼散射的蛋白质疾病标志物检测研究进展
}

\author{
贺晖周玲俐刘震* \\ (南京大学化学化工学院 生命分析化学国家重点实验室 南京 210023)
}

\begin{abstract}
摘要 异常的蛋白质表达与疾病的发生与发展密切相关, 因此蛋白质已作为疾病标志物广泛应用于疾病的早期诊断、 治疗监测和预后评估. 然而, 临床样本中的蛋白质疾病标志物通常含量极低, 并存在高丰度的基质干扰, 对检测方法 的特异性和灵敏度提出挑战. 目前, 蛋白质疾病标志物的检测方法主要是免疫分析. 但是, 免疫分析主要依赖抗体进 行特异性识别, 而抗体具有不易制备、稳定性较差和成本高等缺点. 同时, 免疫分析常通过荧光和化学发光等技术实现 高灵敏检测, 但存在操作繁琐、光漂白、光谱宽等不足. 分子印迹聚合物已发展成为在特异性和亲和力方面可媲美抗 体的仿生识别材料, 且具有容易制备、稳定性好和成本低等优势. 表面增强拉曼散射技术具有超高灵敏度、光谱窄、 快速、无损检测等优势而广泛应用于化学和生物分析. 近年来, 分子印迹技术和表面增强拉曼散射技术的结合产生了 系列先进的蛋白质检测方法, 展现了独特的优势, 受到了广泛的关注. 本综述旨在介绍该联用分析技术的主要进展, 在分别介绍分子印迹和表面增强拉曼散射及其在蛋白质检测中单独应用的基础上, 着重介绍基于两种技术的蛋白质疾 病标志物的检测方法的研究进展. 最后, 对该联用技术的未来发展做了展望.
\end{abstract}

关键词 分子印迹聚合物; 表面增强拉曼散射; 蛋白质; 检测; 疾病标志物

\section{Advances in Protein Biomarker Assay via the Combination of Molecular Imprinting and Surface-enhanced Raman Scattering}

\author{
He, Hui Zhou, Lingli Liu, Zhen* \\ (State Key Laboratory of Analytical Chemistry for Life Science, School of Chemistry and Chemical Engineering, \\ Nanjing University, Nanjing 210023, China)
}

\begin{abstract}
Abnormal protein expression closely correlates with the occurrence and development of diseases. Thus, proteins have been widely used as disease markers for early diagnosis, treatment monitoring and prognosis evaluation of diseases. However, protein biomarkers in clinical samples are usually present in extremely low concentration while the detection often suffers from severe interference by high-abundance sample matrix, which challenges the specificity and sensitivity of protein biomarker assay methods. Currently, the main detection method of protein biomarkers is immunoassay. Nevertheless, immunoassay mainly relies on antibodies for specific recognition, and antibodies are associated with disadvantages such as difficulty in preparation, poor stability, and high-cost. Meanwhile, immunoassay is mainly based on fluorescence and chemiluminescence to achieve high-sensitivity detection, but they have inherent defects such as cumbersome operation, photobleaching and broad spectrum. Molecularly imprinted polymers (MIP) have developed as biomimetic recognition materials with antibody-comparable specificity and affinity, while offering advantages such as ease in preparation, good stability and low cost. On the other hand, surface-enhanced Raman scattering (SERS) has been widely used in chemical or biological assays due to its merits including ultra-high sensitivity, narrow spectrum, speed, non-destructivity, and so on. In recent years, the combination of molecular imprinting and SERS has generated a series of advanced protein detection methods that exhibited unique strengths, which has gained wide attention. This review aims to survey the main advances of this hybrid analytical technique. After introduction of MIP and SERS as well as their separate applications in the detection of protein biomarkers, we mainly focus on the combination of MIP and SERS as well as its application in protein biomarker detection. We finally briefly sketch the future development of this hybrid analytical method.
\end{abstract}

Keywords molecularly imprinted polymer; surface-enhanced Raman scattering; protein; detection; disease biomarker

\section{1 引言}

疾病标志物是进行疾病诊断的重要依据，通常包括 蛋白质、核酸和小分子代谢物等 ${ }^{[1-6]}$. 其中, 蛋白质是常
用的疾病标志物类别之一，在疾病进展的早中晚期具有 多种重要的临床用途，如疾病早期诊断、治疗过程监测 和治疗后复发判定等 ${ }^{[7-9]}$. 然而, 大多数蛋白质疾病标志 物在临床样本中的含量极低, 其检测受高丰度基体组分

* E-mail: zhenliu@nju.edu.cn

Received August 14, 2020; published November 27, 2020.

Project supported by the Key Scientific Instrument and Equipment Development Project (No. 21627810) and the Key Grant (No. 21834003) of the National Natural Science Foundation of China.

项目受国家自然科学基金重大科研仪器研制项目(No. 21627810)及重点项目(No. 21834003)资助. 
的干扰严重. 因此, 如何实现蛋白质疾病标志物的高专 一性和高灵敏度检测一直是临床诊断的关键问题.

目前，已存在多种检测蛋白质疾病标志物的方法， 包括光学检测法(比色法 ${ }^{[10]}$ 、苂光光谱法 ${ }^{[11-13]}$ 、拉曼光 谱法 ${ }^{[14-18]}$ 等)、电学和电化学检测法(包括电化学发光 ${ }^{[19]}$ 、

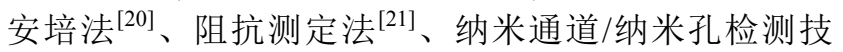

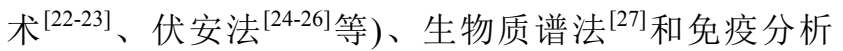
法 ${ }^{[28-30]}$ 等. 其中, 电学/电化学检测具有简便、高灵敏及 易实现便携式操作 ${ }^{[31]}$ 等优势, 但生理条件下受环境影 响大故检测稳定性较差. 生物质谱在蛋白检测方面具有 分辨率高、鉴定准确、信息容量大以及便于和色谱结合 进行定量分析等优点, 但其设备尺寸较大、维护成本高、 操作要求高. 免疫分析因其具备高特异性和高灵敏度的 优势, 应用最为广泛. 其中, 经典的酶联免疫吸附分析 (ELISA)或化学发光免疫分析(CLIA)依靠抗体对目标蛋 白质进行特异性识别, 并通过荧光或化学发光信号实现 目标蛋白质的定量分析. 但其面临两个主要问题：其一, 抗体价格昂贵、制备繁琐且质量不稳定; 其二, 荧光和 化学发光需要引入标记试剂或反应物, 不利于保持抗体 稳定性且易受环境干扰导致信号稳定性受影响. 因此, 开发灵敏度高、特异性强、成本低、稳定性好的检测方 法具有十分重要的意义.

基于分子印迹(MI)技术与表面增强拉曼散射(SERS) 技术的蛋白质检测方法是近年来兴起并受到广泛关注 的新策略. 一方面, 利用 MI 技术制备的分子印迹聚合 物(MIP), 不仅具有优异的识别性能, 如可以妶美抗体 的特异性和亲和力, 还具可定制合成、制备方便、储存 稳定性好且成本低的优势 ${ }^{[32-35]}$. 另一方面, SERS 具有灵 敏度高、光谱分辨率高、响应时间短和显示分子指纹信 息等优点. 与发光光谱相比, 拉曼光谱主要有三个优势: (1)更好的光稳定性 ${ }^{[36]}$; (2)光谱宽度更窄且可显示分子 结构信息 ${ }^{[37-38] ;}$; (3)可实现信号的指数级增强 ${ }^{[39]}$. 结合两 类技术的优势，可同时实现高特异、高灵敏、高稳定性、 低成本及反映分子指纹信息等传统技术难以达到的检 测.

目前, 已有少数介绍 MI 与 SERS 联用分析的综

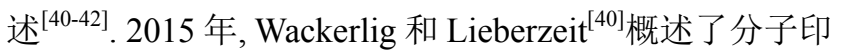
迹纳米颗粒在 SERS 传感中的应用并预测了其巨大的发 展潜力. 2018 年, Reineke 和 Haynes 等 ${ }^{[41]}$ 从聚合方法的 角度出发概括了 MI 与 SERS 联用方式. 最近, 陈令新 等 $^{[42]}$ 总结了基于 MI 的 SERS 传感器研究进展, 主要介 绍了针对小分子的印迹和分析策略. 本综述以蛋白质疾 病标志物这类具有重要临床应用价值的生物大分子为 对象, 在分别介绍了 MI 和 SERS 应用于蛋白质疾病标 志物检测的研究进展的基础上, 着重阐述了基于 MI 和 SERS 联用的蛋白质疾病标志物的检测新策略. 最后, 对该联用技术在未来蛋白疾病标志物检测的发展方向 进行展望.

\section{2 分子印迹}

\section{1 分子印迹技术简介}

分子印迹的基本原理如图 1 所示. 首先, 通过功能 单体与模板分子相互作用, 形成模板-功能单体复合物, 然后诱导功能单体与交联剂聚合, 将模板分子洗脱后, 即可形成与模板分子三维空腔匹配的 MIP. MIP 具有在 大小、形状和官能团分布上与模板互补的印迹空腔, 可 对模板分子进行特异性识别 ${ }^{[43-47]}$. 由于其仿生识别能力 突出, MIP 已在很多领域中显示独特的应用潜力, 例如

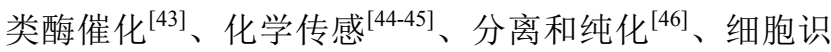
别 ${ }^{[47-48]}$ 、癌症光热治疗 ${ }^{[49]}$ 和抗肿瘤纳米药物 ${ }^{[50]}$ 等. 作为 人工抗体, MIP 不仅能高亲和力和特异性对目标蛋白进 行识别，还可根据目标蛋白特性实现定制合成，也具有 优良的储存稳定性、可抗恶劣环境和可重复使用性等优 点, 其在过去十年中得到广泛应用 ${ }^{[51-53]}$.

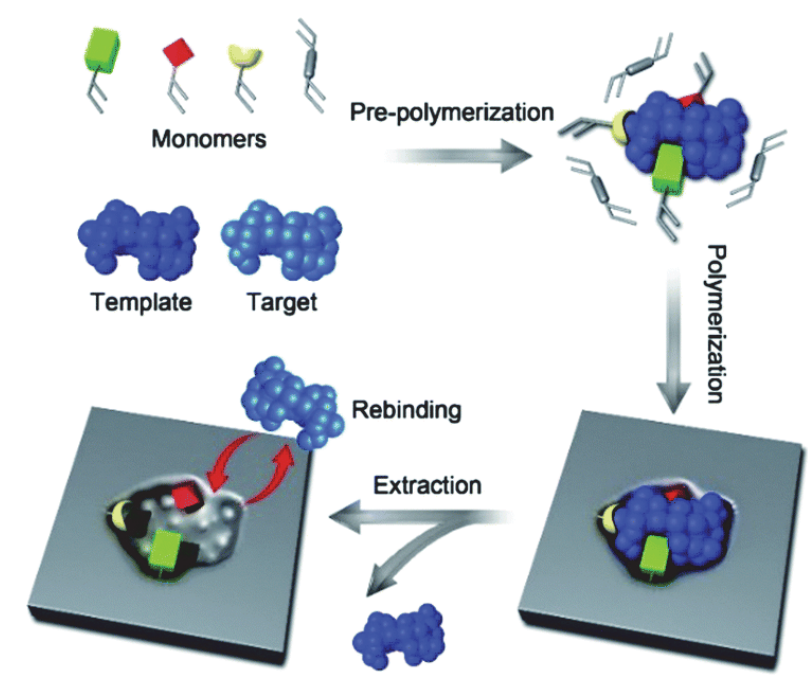

图 1 分子印迹的原理示意图 ${ }^{[47]}$

Figure 1 Schematic of the principle of molecular imprinting ${ }^{[47]}$

\section{2 蛋白质分子印迹策略}

传统的蛋白质印迹通常要使用完整蛋白作为模板, 会遇到以下两个挑战 ${ }^{[54]}$ : (1)常用的聚合体系不利于保持 模板蛋白的天然构象而导致印迹空腔不匹配; (2)低丰度 蛋白很难获得足够的高纯度模板蛋白用于印迹. 目前的 解决方案主要有两类: 控制聚合反应和识别特征片段.

\subsection{1 完整蛋白印迹}

印迹聚合反应通常在高温、极端 $\mathrm{pH}$ 及有机相等苛 刻的条件下进行, 这会导致蛋白质构象变化甚至是严重 变性, 而且大分子的蛋白质模板在印迹聚合物网络中难 以去除，导致识别效率低等问题 ${ }^{[55]}$. 通过改变聚合体系 或聚合方式可以改善这一状况. 表面印迹法可有效地解 决模板去除困难的问题 ${ }^{[56-57]}$, 将蛋白质分子固定在印迹 材料的表面附近可以增大其扩散能力，有效释放印迹空 腔便于重新识别. 为提高模板利用率, Piletsky 等 ${ }^{[58-59]}$ 提 
出了一种固相模板印迹法, 先将模板固定到固相基底表 面，通过光聚法进行印迹，先在低温下将亲和力低的非 印迹材料清除, 再在高温条件下将高亲和力的印迹材料 洗脱并收集, 得益于模板固定的策略, 模板可以反复多 次用于印迹材料的制备，可实现印迹材料的批量制备. 利用这种原理, Haupt 等 ${ }^{[60]}$ 在固相基底上先修饰过氧化 氢酶, 并利用其催化特性引发自由基聚合同时引入模板 分子进行印迹, 实现了蛋白印迹材料的绿色制备. Sellergren 等 ${ }^{[61]}$ 报道了一种磁性模板固相合成蛋白质印迹 材料的方法, 将蛋白质模板先固定到磁性纳米颗粒表面 后再在聚合体系中制备印迹材料, 经变温将印迹材料洗 脱, 并通过磁分离高效地去除模板, 可得到高亲和力的 蛋白印迹的纳米凝胶. 然而, 固相模板印迹法中聚合是 在有机相中进行且印迹材料的洗脱需要通过低温高温 切换, 这些条件均会导致部分蛋白的变性进而使得印迹 材料的性能降低或不稳定. 但该方法具有模板可重复利 用的优势, 若能够解决印迹条件苛刻并通过温和的方式 进行材料洗脱收集则有利于蛋白标志物等稀有蛋白印 迹材料的批量制备. 皮克林(Pickering)乳液印迹可以在 水相中进行聚合和印迹 ${ }^{[62]}$, 沈先涛等 ${ }^{[63]}$ 利用油包水的 皮克林乳液体系实现了完整蛋白在保持构象条件下的 印迹, 得到高选择性的印迹材料, 并将该方法扩展至更 大尺寸的细菌的印迹 ${ }^{[64]}$. 缩短聚合时间也可以有效地 保留完整蛋白的构象. 刘震等 ${ }^{[34]}$ 提出了光刻嗍亲和分 子印迹法(图 2), 利用常温下的紫外光引发快速聚合反 应(聚合时间为几十秒), 避免了蛋白质模板长时间聚合 时构象的变化甚至是变性. 同时, 由于在聚合体系中加 入了致孔剂, 所得印迹材料具有多孔结构, 有利于大分 子模板在印迹后的去除. 更为重要的是, 该方法展现了 超出正常预期的多个高度有利的特征, 特别是超强的抗 干扰能力和更宽的结合 $\mathrm{pH}$. 血液等生理样品中含有大 量的单糖, 单糖的干扰是对所得材料的识别性能的重要

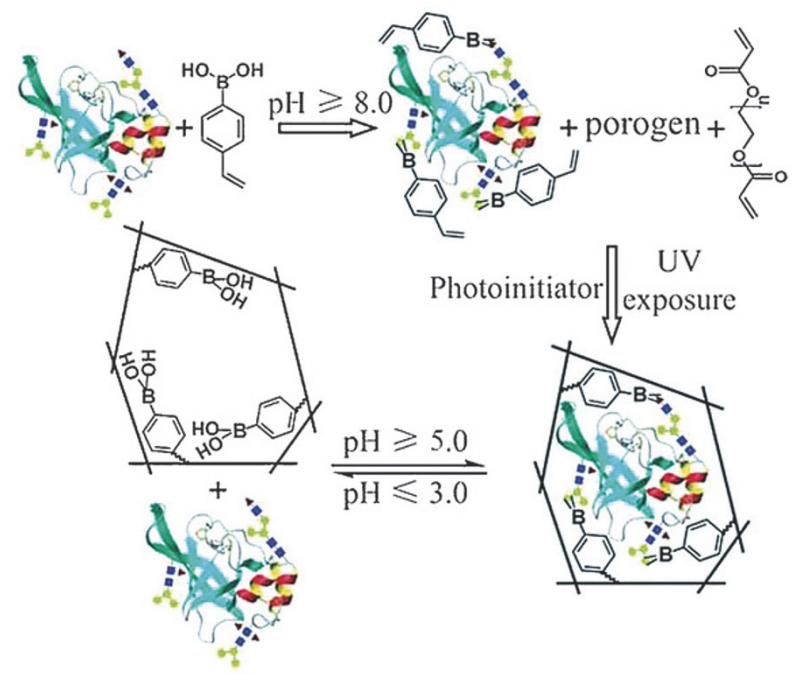

图 2 光刻嗍亲和分子印迹法原理示意图 ${ }^{[34]}$

Figure 2 Schematic of the principle of photolithographic boronate affinity molecular imprinting ${ }^{[34]}$
考验. 利用该方法所得印迹材料能抗 1 百万倍单糖的干 扰. 这主要是由于所得印迹材料对目标糖蛋白的结合能 力和单糖比较提高了 6 个数量级. 此外, 在非印迹条件 下，嗍亲和材料对糖蛋白的结合需要较高的 $\mathrm{pH}$ (通常高 于 8.0), 而通过印迹后所得材料对目标糖蛋白的结合 $\mathrm{pH}$ 大幅降低至 5.0, 从而使得分子印迹嗍亲和材料的适用 范围大大扩宽. 该方法是一个针对糖蛋白设计的通用、 便捷和高效的印迹方法, 克服了以往印迹方法通用性和 便捷性差的局面. 当目标糖蛋白不同时, 无须从头设计 印迹路线，只需要对印迹体系做适当微调即可.

然而, 该方法存在一定局限性: 当材料较厚, 光无 法穿透或者印迹部分无法接受光照时，该方法无法适用. 鉴于此, 刘震等继续发展出以聚多巴胺 ${ }^{[65]}$ 或聚苯胺 ${ }^{[66-67]}$ 水相自聚合体系为基础的嗍亲和表面定向印迹法. 先利 用硼亲和作用将模板糖蛋白固定在硼亲和基底材料上， 然后利用自聚合体系制备印迹层覆盖模板分子到合适 的厚度. 该方法由于聚合反应在水相中进行，可以充分 保持模板蛋白的构象.同时，由于印迹发生在表面，模 板的去除容易, 得到的有效印迹空腔数目多. 更为重要 的是, 在这样的印迹体系中得到的印迹层厚度在一定范 围内与印迹时间成正比, 印迹层厚度可根据目标糖蛋白 的分子尺寸预测, 方法具有较好的可控性.

\subsection{2 糖表位印迹}

以完整蛋白为模板进行印迹时, 一个限制因素是很 多目标蛋白质的纯品很难获得. 以蛋白质的特征片段作 为印迹模板可很好地解决该问题, 不仅从根本上克服了 印迹条件下蛋白质构象变化的问题，同时能制备识别性 能优良的印迹材料. 考虑到多数疾病标志物蛋白均为糖 蛋白，而糖蛋白上含有一类重要的结构单元一一聚糖， 其对蛋白质的结构及功能有重要影响 ${ }^{[68-69]}$, 而聚糖在常 规聚合反应体系中相对稳定，故对聚糖这类特征片段进 行印迹可克服蛋白质构象易变的问题. 同时, 由于聚糖 的免疫原性差, 其抗体的制备非常困难, 制备能高选择 性识别聚糖的印迹材料具有重要科学意义. 刘震等 ${ }^{[70-71]}$ 利用嗍亲和定向表面分子印迹技术可方便地合成能够 专一性识别糖蛋白表面聚糖的人工抗体, 其不仅可以用 于识别完整糖蛋白，还可以识别其特征碎片，如特征性 的糖肽和聚糖，对于半衰期短的不稳定蛋白质，即便其 发生降解也可以高效地进行识别并通过质谱进行鉴定, 克服了传统方法难以检测易降解蛋白质的缺陷. 基于以 上方法总结了一套适用于单糖、聚糖及糖蛋白等含顺式 二羟基化合物的通用的印迹方法(图 3) ${ }^{[72]}$ : 在印迹过程 中首先以嗍亲和作用为针定位点, 将模板分子固定到基 底表面; 然后选择合适的聚合体系进行印迹，印迹层厚 度可通过聚合时间进行调控，以得到最佳的印迹效果； 最后，将模板洗脱后得到表面富含印迹空腔的材料. 该 方法不仅提高了印迹材料的亲和力和选择性，也提供了 方便的结合/洗脱模式，不仅对于糖蛋白疾病标志物的 
印迹提供了一种高效的解决方案, 也可以针对各种含糖 类等免疫原性差的目标物可控、方便、高效地制备人工 抗体 ${ }^{[73-75]}$. 唾液酸是一种特殊的单糖表位, 通常表达于 糖蛋白上聚糖末端, 参与了众多重要的生理病理调 节 $^{[76]}$, 因此制备可特异性识别唾液酸的印迹材料具有 重要意义. 作为一种小分子, 对唾液酸的印迹体系选择 相对灵活, 一般不需考虑印迹体系对其构型的影响, 需 要关注的是唾液酸的印迹材料的识别响应. Sellergren 等 ${ }^{[77]}$ 利用可逆加成-断裂链转移聚合法, 在印迹唾液的 同时加入苂光染料分子, 制备的 MIP 可用于细胞表面唾 液酸的标记. Haupt 等 ${ }^{[78]}$ 通过光聚法在量子点表面制备 了识别唾液酸的 MIP 并用于细胞成像. 刘震 等 ${ }^{[48-49,73,78-79]}$ 利用嗍亲和定向表面印迹法制备了系列具 有不同信号响应的可特异性识别唾液酸的 MIP, 分别用

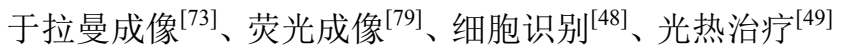
及智能前药递送 ${ }^{[80]}$.

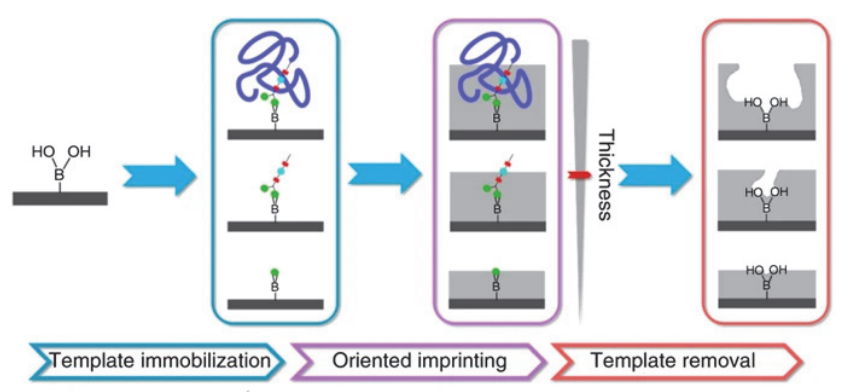

\& Glycoprotein of Glycan - Monosaccharide $\square$ Substrate Imprinting layer

图 3 硼亲和可控定向表面印迹法原理示意图 ${ }^{[72]}$

Figure 3 Schematic of the principle of boronate affinity controllableoriented surface imprinting ${ }^{[72]}$

\subsection{3 肽表位印迹}

表位多肽是位于蛋白质 $\mathrm{N}$ 或 $\mathrm{C}$ 末端的具有特定氨 基酸序列的结构单元. 表位多肽能够作为蛋白质的特征, 因此通过识别表位多肽即可实现对含该表位的蛋白质 的识别. 表位印迹即是以蛋白质的表位多肽为模板的印 迹. 由于表位是蛋白质的特征序列, 故表位印迹所产生 的空腔既能识别表位, 又能识别目标蛋白. 与完整蛋白 模板相比, 表位模板通常不存在高级结构, 因此在印迹 过程中不涉及构象变化问题. 即使对于稀有蛋白质, 也 可方便地通过人工合成的方式获得表位模板用于印迹. 表位印迹法在设计上类似于抗原与抗体识别域的结合, 因此与天然识别方式更接近, 这有利于在生物样品中实 现对靶标的高特异性识别. 目前已开发了多种不同类型 的表位印迹技术应用于完整蛋白或肽识别. Shea 等 ${ }^{[81-82]}$ 利用不同的丙烯酸和丙烯酰胺类单体与表位多肽相互 作用并引发沉淀聚合实现印迹, 通过优化配比可获得对 多种蛋白特异性识别的聚合物纳米颗粒 ${ }^{[83-85]}$. Sellergren 等 ${ }^{[86]}$ 同样以多种丙烯酰胺单体与表位多肽作用并聚合 后, 通过基底剥离的方式去除模板后得到对含有模板的 蛋白具有高亲和力的印迹材料, 特别是对疏水末端蛋白
或细胞黏附蛋白有良好的识别性能 ${ }^{[87-88]}$. Piletsky 等 ${ }^{[89]}$ 利用固相模板法将表位多肽先固定到固相基底上再进 行印迹, 并在印迹过程中引入抗肿瘤药物, 制备的印迹 材料可实现抗肿瘤药物的靶向递送. Haupt 等 ${ }^{[90]}$ 以细胞 表面钙粘蛋白上一段高度保守的肽表位为模板, 通过固 相模板法制备了其印迹材料并用于抑制细胞黏附. 基于 表位多肽在有机聚合体系中的稳定性，其可在多种聚合 体系中进行印迹，并可根据不同聚合物的性质制备具有 不同信号响应的功能性印迹材料. 潘国庆等 ${ }^{[91]}$ 制备了 一种短肽印迹的热响应水凝胶，可用于捕获和黏附细胞 并通过温度调节脱附以获得细胞层从而便于其它生物 医学研究. 李文友等 ${ }^{[92-93]}$ 通过溶胶-凝胶法制备了具有 不同光学响应并携带药物的表位印迹纳米材料，可用于 癌细胞的靶向苂光成像、药物递送及光动力学治疗. 张 丽华等 ${ }^{[94-95]}$ 通过自组装的方式制备了表位印迹的聚苯 醚砜微球，可用于捕获血清中一种或多种靶蛋白用于蛋 白质组学分析, 有效地克服了基质干扰的问题.

尽管现有的表位印迹法在蛋白质识别方面取得了 成功, 但在方法设计上仍存在问题. 首先, 一些方法中 使用表位末端氨基酸的氨基或颈基作为固定模板的位 点 ${ }^{[96-97]}$, 但其它氨基酸上也可能存在这些基团会改变表 位多肽印迹时的构型从而降低印迹空腔的识别性能. 若 不进行模板固定, 则印迹时模板取向随机变化会使部分 模板被掩埋而导致印迹效率降低 ${ }^{[98-99]}$. 此外, 多数表位 印迹法针对的是特定目标物不具有通用性, 对于新靶标 的印迹还需要重新进行繁琐的优化. 为解决上述问题, 刘震等 ${ }^{[100]}$ 开发了嗍亲和针定的定向表面印迹法. 该方 法的原理如图 4 所示, 通过化学方法在表位末端修饰上 一个单糖, 以其作为模板, 通过嗍亲和作用将糖化表位 固定到基底材料表面; 由于嗍亲和作用只于单糖分子结 合并不会影响表位构象，故可以保证表位模板以定向的 方式固定于基底材料表面; 随后，以多种硅烷化试剂为 功能单体通过时间控制的可控聚合，即可方便地制备特 异性识别该表位的印迹材料，其可对未修饰的天然表位 及蛋白质进行高亲和力和高选择性识别. 基于喼亲和针 定糖化表位的策略, 该法可以方便地应用于任意蛋白质 的表位印迹, 通用性强, 为实现更多蛋白质疾病标志物 的识别与检测奠定了基础. 另外, 基于硼酸功能化具有 良好的基底材料兼容性 ${ }^{[101]}$ ，硼亲和针定的定向表面印 迹可在多种基底表面进行从而得到具有不同功能的特 异性识别材料，例如分别在自组装金 $(\mathrm{Au})$ 纳米颗粒和银 (Ag)基拉曼纳米标签表面针对目标蛋白的 N、C 两端分 别进行印迹，即可对目标蛋白进行高特异性捕获和标 记，从而实现专一高灵敏的检测 ${ }^{[102]}$. 尽管对模板多肽 进行糖化处理相比于天然模板多了一步化学修饰, 但这 仅是为了制备印迹材料, 一旦获得了具有最优识别性能 的 MIP 后, 应用时不需要对蛋白进行糖化处理, 可以直 接用于捕获天然蛋白. 相比于无糖化处理, 虽然模板需 


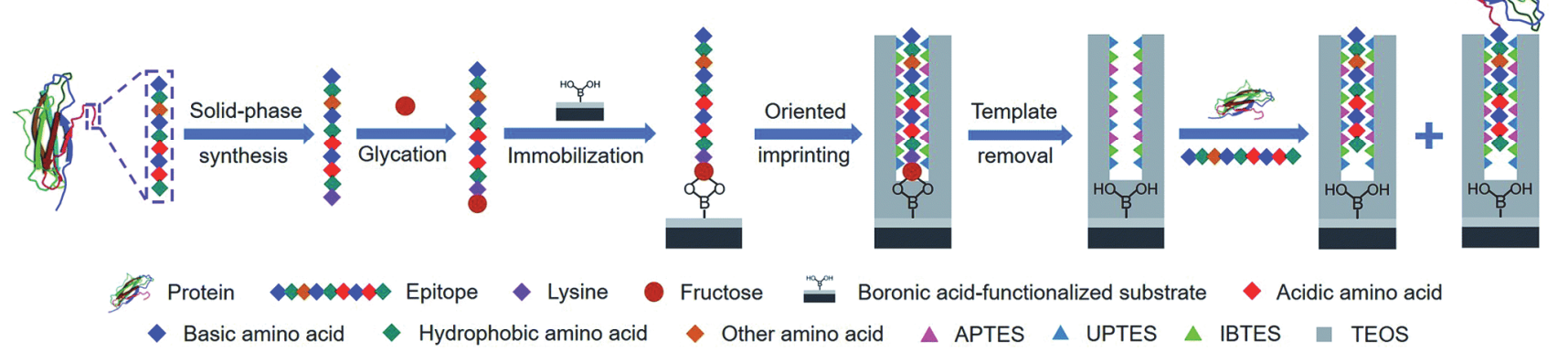

图 4 嗍亲和针定的可控定向表位印迹法原理示意图 ${ }^{[100]}$

Figure 4 Schematic of the principle of controllable oriented surface imprinting of boronate affinity-anchored epitopes ${ }^{[100]}$

要多一步糖化修饰, 但制备印迹材料在时间、成本等方 面并无明显区别, 且得到印迹材料在选择性和亲和力方 面的性能要远强于传统方法. 相比于目前临床诊断依赖 抗体，该方法还可以针对目前还无法或难以制备抗体的 标志物制备其印迹材料进行特异性识别检测, 并具有可 批量制备及重复多次使用等优势.

\section{3 分子印迹技术应用于蛋白质疾病标志物的分析}

随着印迹技术的发展, 针对蛋白质的 MIP 制备技术 已逐渐成熟, 从而被广泛应用于复杂体系中蛋白质疾病 标志物的高专一性检测, 通常包括热传感 ${ }^{[103]}$ 、光学检 测 ${ }^{[104-106]}$ 和电化学分析 ${ }^{[107-112]}$ 等. 将分子印迹聚合物浸 涂到热电偶上, 并通过监测流通池中的液体温度来实现 对心脏脂肪酸结合蛋白质和生长刺激表达基因 2 蛋白的 同时测量 ${ }^{[103]}$. 通过分子印迹策略并使用电化学方法将 导电聚甲苯胺蓝用作合成受体膜, 成功应用于血清中癌 抗原 15-3 (CA15-3)的检测 ${ }^{[110]}$. 热传感和电化学分析平 台具有简单、低成本和高选择性的优点, 但对环境要求 较高, 每次测量前均需稳定一段时间, 导致测量时间较 长. 张玉奎和李文友等 ${ }^{[105]}$ 通过表位印迹法制备了一种 新型的荧光传感器 (图 5), 即氮掺杂石墨烯量子点/ $\mathrm{SiO}_{2} / \mathrm{MIP}$, 可以用于识别和检测细胞色素 $\mathrm{C}$ (Cyt C). 基 于 Cyt C 对量子点荧光的淬灭作用, 通过材料与目标物 结合后信号响应减弱实现了对 Cyt C 的检测, 其线性范 围是 $0.20 \sim 60 \mu \mathrm{mol} / \mathrm{L}$, 检测限为 $0.11 \mu \mathrm{mol} / \mathrm{L}$. 该方法中, 引入金属螯合作用使模板固定的更加牢固, 但检测灵敏 度有待提高. 上述方法中使用了 MIP 可实现稳定、快速、 低成本和高特异性的靶蛋白识别, 但如何进一步提高蛋 白质疾病标志物的检测灵敏度有待进一步发掘.

\section{3 表面增强拉曼散射}

\section{1 表面增强拉曼散射简介}

拉曼散射是入射光与样品相互作用后产生的非弹 性散射, 其反映的是样品中分子振动信息, 故可以反映 样品的分子特征(图 5), 然而由于这类散射光的信号极 低(仅占全部散射光的 $0.1 \%$ ), 故早期难以直接用于样品

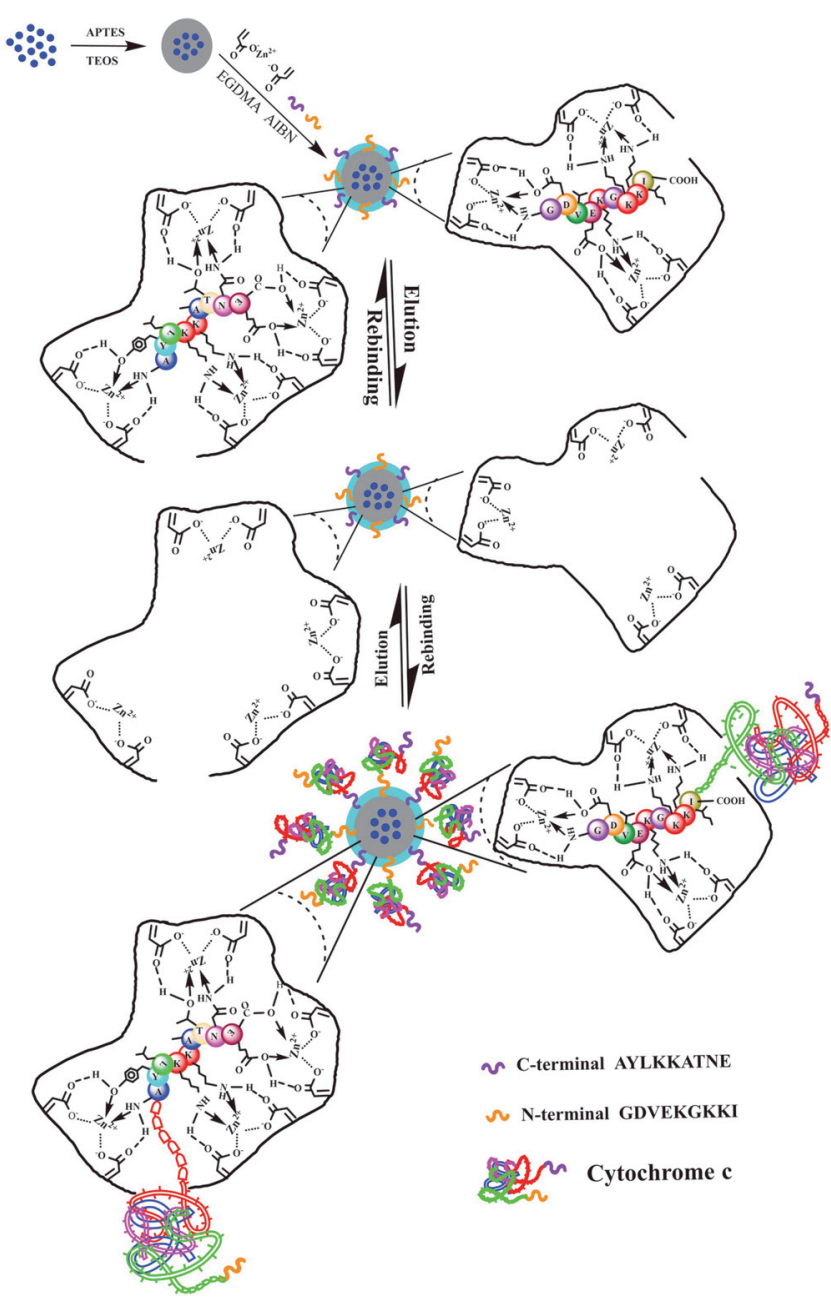

图 5 基于 MIP 苂光传感器应用于 $\mathrm{Cyt} C$ 的检测原理示意图 ${ }^{[105]}$ Figure 5 Overview of MIP-based fluorescence sensor applied to Cyt C

分析, 直至表面增强拉曼散射(SERS)的出现. 当分子吸 附在具有纳米结构的贵金属表面上时，分子的拉曼散射 得到大幅增强，为其用于高灵敏的分析检测奠定了基 础. 目前普遍认可的两种增强原理是化学增强机制 $(\mathrm{CM})$ 和电磁增强机制 $(\mathrm{EM})^{[113-114]}$. 化学增强通常只有 $10 \sim 100$ 倍, 而电磁增强可高达 $10^{11}$ 倍, 故 $\mathrm{EM}$ 起主导作 
用 ${ }^{[115-117]}$. EM 的核心原理是金属表面自由电子在光的照 射下发生等离激元共振(SPR) 导致吸附分子的拉曼响应 显著提升(图 6). 尽管其具体的增强机制还有待进一步 探究, 但不影响 SERS 在超灵敏检测方面的应用. 基于 这些增强效应, SERS 的检测灵敏度在某些情况下可达 到单分子水平, 这对于低丰度目标物的检测具有重要的 意义. 更为详细的 SERS 研究进展参见其它相关的综 述 ${ }^{[118-122]}$.

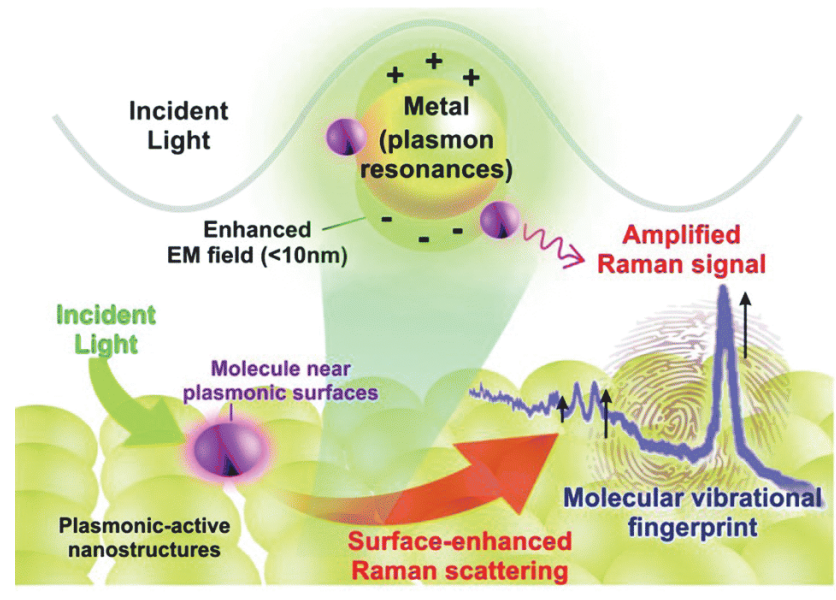

图 6 SERS 和 SERS 的电磁增强机理 ${ }^{[117]}$

Figure 6 SERS and its electromagnetic enhancement mechanism ${ }^{[117]}$

\subsection{SERS 应用于蛋白质类疾病标志物的分析}

SERS 由于其高灵敏、无损和能显示分子指纹信息 等优点而被广泛应用于蛋白质疾病标志物的高灵敏检 测. 目前, 基于 SERS 的蛋白质疾病标志物的检测可分 为直接 SERS 检测和间接 SERS 检测 ${ }^{[123]}$.

由于生色团在共振条件下通常具有大的拉曼散射 截面, 一些包含生色团的蛋白质(例如, Cyt C、血红蛋白 和肌红蛋白等), 可以通过直接增强目标蛋白的拉曼信 号的方式进行检测 ${ }^{[124-130]}$. 任斌等 ${ }^{[124]}$ 提出了一种利用碘 化物修饰的 $\mathrm{Ag}$ 纳米颗粒直接检测蛋白质的策略. 如图 7 所示, $\mathrm{Ag}$ 表面包覆的碘化物层可以在去除表面杂质的 同时阻止蛋白质与金属颗粒的直接相互作用, 实现了保 持蛋白质的天然构象的直接 SERS 分析. 利用这种方法 可获得五种典型蛋白(溶菌酶、抗生物素蛋白、牛血清 白蛋白、Cyt C 和血红蛋白)的高重现性 SERS 信号. 不 同于隔层检测蛋白质, Matteini 等 ${ }^{[128]}$ 将 $\mathrm{Ag}$ 纳米立方体 的角点直接接触蛋白质, 实现了 Cyt C 的直接 SERS 检 测. 由于立方体表面包裹了聚乙烯基吡咯烷酮(PVP)涂 层, Cyt C 不会与立方体的面直接接触, 而会优先与立方 体的角点(此处 PVP 的量很少)接触, 这极大地降低了吸 附方式的变动带来的信号波动, 从而显著提高了拉曼信 号的重现性. 尽管上述方法能实现光谱的高重现性, 但 是由于缺乏选择性, 不能直接应用于复杂体系. 另外, 韩晓霞等 ${ }^{[130]}$ 制备了具有还原性的 $\mathrm{Ni}$ 纳米线, 其可以选 择性地结合氧化型 Cyt C 并区分 Cyt C 的氧化还原状态,
同时利用 $\mathrm{Ag}$ 纳米颗粒的 SERS 效应实现无标记的高灵 敏 Cyt C 分析(检测限为 $1 \mathrm{nmol} / \mathrm{L}$ ). 此方法中, 利用 $\mathrm{Ni}$ 纳米线的磁性可以很方便地将 Cyt C 从复杂基质中分离, 但选择性是针对特定蛋白质不具有普适性.

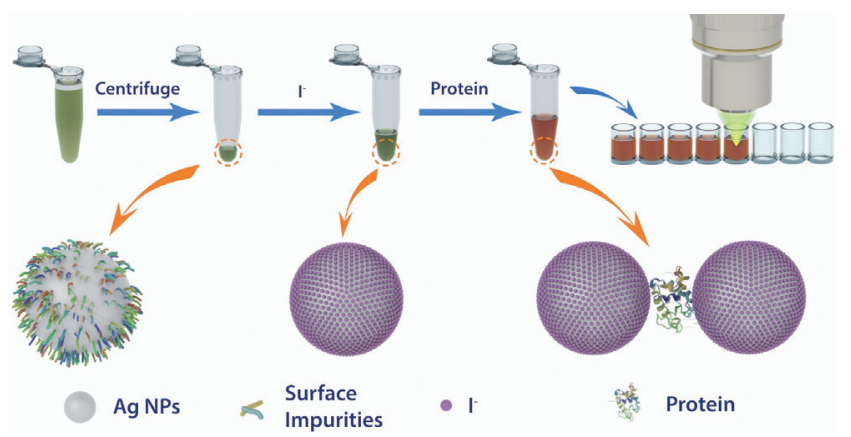

图 7 蛋白质无标记 SERS 检测的原理示意图 ${ }^{[124]}$

Figure 7 Overview of label-free SERS detection of protein ${ }^{[124]}$

为了实现对无拉曼响应或响应较低的目标的高灵 敏检测，可以利用增强拉曼报告分子的信号结合特异性 识别的方式，间接地对目标蛋白进行检测 ${ }^{[131-137]}$. 目前， 蛋白质间接 SERS 检测主要是基于抗体或适配体对目标 蛋白特异性识别. 如图 8 所示, 沈爱国等 ${ }^{[131]}$ 成功制备了 $\mathrm{C} \equiv \mathrm{N}$ 和 $\mathrm{C} \equiv \mathrm{C}$ 编码的 SERS 标签标记的 $\mathrm{Au}$ 纳米颗粒, 并结合磁珠分离和富集, 发展了一种无干扰的混合型 SERS 示数的方法实现了三种特定的肝癌抗原的同步检 测，包括甲胎蛋白(AFP)、癌胚抗原(CEA)和铁蛋白，检 测限分别为 $0.15 、 20$ 和 $4 \mathrm{pg} / \mathrm{mL}$. 李国梁等 ${ }^{[132]}$ 制备了 $\mathrm{Au}$ 纳米颗粒掺杂的共价有机框架化合物(COF)用作纳 米酶催化 4-硝基苯硫酚为 4-氨基苯硫酚, 并在此基础上 建立了一种新型比率 SERS 免疫吸附测定法, 用于乳球 蛋白的高灵敏检测. 得益于纳米酶介导的比率拉曼信号 放大输出该方法的灵敏度大大提高, 检测限为 0.01 $\mathrm{ng} / \mathrm{mL}$. 另外, 黄承志等 ${ }^{[133]}$ 构建了抗体-抗原-适配体的 夹心结构, 以 4-颈基苯甲酸为报告分子, 提出了基于连

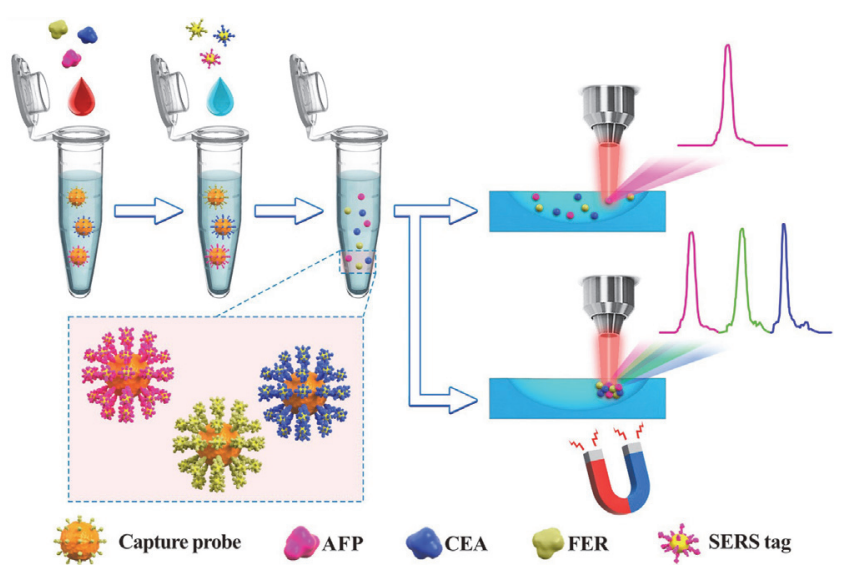

图 8 基于 SERS 的肝癌抗原多重检测过程 ${ }^{[131]}$

Figure 8 Schematic representation of the process of SERS-based multiplex detection of liver cancer antigens ${ }^{[131]}$ 
锁杂交链式反应用于总前列腺特异性抗原(tPSA)的超灵 敏 SERS 免疫测定, 检测限可低至 $0.94 \mathrm{fg} / \mathrm{mL}$, 并成功用 于前列腺癌患者临床血清样本中 tPSA 含量的测定. 上 述间接 SERS 检测虽具有较高的灵敏度, 但是在识别靶 标方面仍依赖抗体. 适配体可以在某些条件下替代抗体, 但其构象易变可能会导致选择性降低, 此外其对生物样 品中的核酸酶不耐受, 故稳定性受到影响. 因此, 发展 能克服抗体和适配体缺点的新型特异性识别方法对于 SERS 间接检测蛋白标志物具有重要的意义.

相比于其它间接检测的方法, 如电化学或苂光等, SERS 有其独特的优势. 首先, 拉曼光谱本身对样品要 求不高, 固液气态样品均可以检测 ${ }^{[109]}$, 因此 SERS 检测 可以在各种基质中进行, 而其它方法的样品覆盖范围均 有限; 然后, 拉曼光谱相对于其它发光光谱谱带更 窄 ${ }^{[37-38]}$, 光谱重叠几率小, 便于实现多元检测; 最后, SERS 增强实现起来相对容易, 在不改变硬件的条件下 通过设计更高效的等离激元纳米结构即可实现, 若配合 小型拉曼光谱仪也便于进行便携式超灵敏检测.

\section{4 基于 MIP 和 SERS 联用的蛋白质疾病标志物 检测}

临床样品中蛋白质疾病标志物的丰度极低且基质 干扰物的丰度较高仍是检测的瓶颈问题, 解决这个问题 的根本途径有两条: (1)高专一的识别; (2)高灵敏的检测. 目前, 基于抗体识别和荧光/化学发光检测的 ELISA 方 法是蛋白质标志物检测的主要方法. 然而, 抗体的成本 及稳定性、苂光的光漂白、化学发光操作复杂耗时等问 题, 限制了该类方法的进一步发展. MIP, 作为一种抗体 替代物, 可以对目标蛋白进行专一性识别, 与抗体相比, 其成本较低、制备方便且性能稳定. SERS, 作为一种高 灵敏检测技术, 相比苂光和发光光谱, 光谱分辨率高、 无光漂白、无损且具有分子指纹信息. 将二者结合, 为 蛋白疾病标志物的检测提供了新的解决方案. 目前, 基 于 MIP 和 SERS 的蛋白质疾病标志物检测主要有两种方 式, 一是基于标记的检测策略, 二是无标记的检测策略.

\section{1 基于标记的检测策略}

基于标记的检测策略中, MIP 用于专一性识别目标 蛋白，而 SERS 检测的信号是来自拉曼报告分子并非目 标分子本身. 尽管这种方式无法获得目标蛋白的分子指 纹信息, 但拉曼报告分子的信号经表面增强后得到显著 提升, 因此对目标蛋白的响应信号得到显著放大, 可以 获得高的检测灵敏度, 故这种方式是目前常见的检测策 略.

\subsection{1 基于 MIP 捕获和非 MIP 的常规标记}

凭借 MIP 对蛋白质的高专一性识别作用, 刘震 等 ${ }^{[138]}$ 开发了硼亲和夹心法(BASA), 该方法利用硼亲和 分子印迹技术可方便地对糖蛋白疾病标志物进行印迹
和捕获，并通过硼酸配基修饰的 SERS 标签标记，从而 形成夹心结构，实现了对糖蛋白疾病标志物的高灵敏检 测. 有趣的是，该工作中，作者观察到基底材料能产生 一定的次级增强效应. 该现象暗示着若对基底材料进行 特殊的选择或设计，可能在 SERS 的基础上进一步提高 检测灵敏度. 该夹心法也被用于血清中癌胚抗原(CEA) 的检测 ${ }^{[139]}$.

受以上次级增强效应的启发, 刘震等 ${ }^{[140]}$ 考察了多 种基底材料与纳米材料的组合后发现，当银基的纳米拉 曼标签与金基的基底组合时，基底和纳米标签产生的电 场会产生耦合, 形成热点, 在 SERS 的基础上信号增强 了约 40 倍. 在此基础上开发了基于表面等离激元的免 疫夹心法(PISA), 该方法的原理如图 9A 所示, 表面修饰 了 MIP 或抗体的金基微萃取探针先将目标蛋白高效专 一地萃取到探针表面, 随后用修饰了能识别目标蛋白的 抗体或硼亲和配基的银基纳米拉曼探针标记，从而形成 萃取探针-目标蛋白-拉曼标签三明治型夹心复合结构, 当激光照射时发生表面等离激元共振，银基拉曼标签产 生表面增强拉曼散射，微萃取探针表面超薄的金层会产 生表面等离子波与银基拉曼标签的表面增强效应耦合 从而进一步增强拉曼散射信号, 信号增强倍数达 9 个数 量级以上，显著增强了检测灵敏度，检测限可达单分子 水平. 得益于耦合增强的机制和高专一性识别, 该方法 避免干扰信号的同时有效构建了均匀分布的热点, 克服 了热点不均一导致的重现性差的缺点, 显著提高了信号 稳定性可用于定量分析. 该方法成功实现了单个活细胞 内低拷贝数蛋白质的检测, 并可以直接拓展到活体动物 体内低丰度蛋白的检测 ${ }^{[140]}$.

基于 PISA 的原理, 可灵活地根据需要选用合适的 拉曼活性标签及识别方式，因而可扩展成为一种通用的 蛋白质疾病标志物分析技术，应用于尿样和血样等复杂 生理样品中糖蛋白的分析. 比如, 在超薄金层覆盖的玻 璃板表面制备可特异性识别和捕获人促红细胞生成素 (EPO)的 MIP 阵列, 并用拉曼活性标签标记后可实现人 尿液中的 EPO 的超灵敏检测(图 9B), 检测限可达 $2.9 \times$ $10^{-14} \mathrm{~mol} / \mathrm{L}$, 对体育活动中兴奋剂的快速检测具有重要 意义 ${ }^{[141]}$. 与此类似, 以 $\mathrm{Au}$ 纳米颗粒自组装的玻璃板为 基底制备甲胎蛋白(AFP)的 MIP 阵列，可用于血清中的 AFP 的快速检测, 检测限为 $1.5 \times 10^{-14} \mathrm{~mol} / \mathrm{L}^{[142]}$. 除了 基于嗍亲和的 MIP, 适配体也可作为配基先固定蛋白质 再通过印迹实现适配体和 MIP 双重作用的更高亲和力 和选择性的识别, 该方法已成功用于血清中的碱性磷酸 酶的高灵敏检测, 定量限为 $6.2 \times 10^{-12} \mathrm{~mol} / \mathrm{L}^{[143]}$. 此外, PISA 技术还可以用于植物果实中单糖的空间分布分 析 $^{[144]}$. 基于此种原理结合核酸序列杂交亲和识别作用 还可构建等离激元亲和夹心法(PASA)用于单细胞和血 清中的 microRNA 的检测 ${ }^{[145-146]}$. 结合适配体识别 PASA 可用于血清和活体动物中蛋白质疾病标志物的检测 ${ }^{[147]}$. 
A

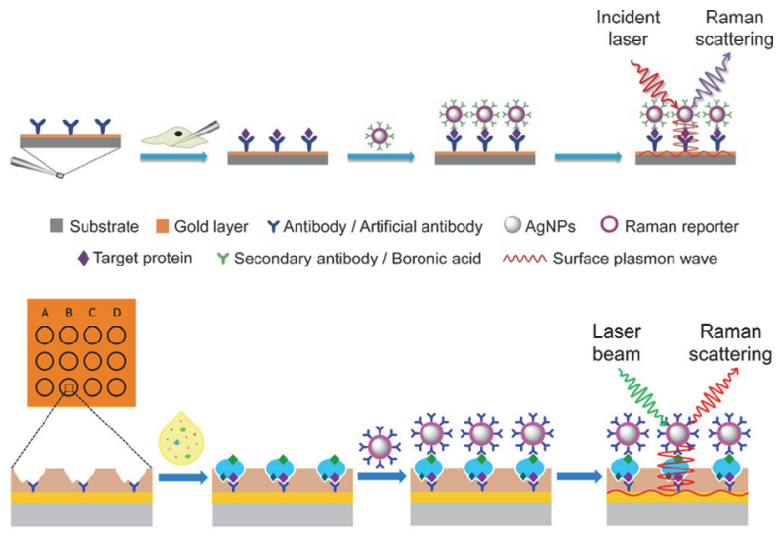

Wubstrate Gold layer —Molecularly imprinted layer YBoronic acid Complex sample

1. Glycoprotein $\leftrightarrow$ Glycans OAgNPs ORaman reporter ఋ Surlace plasmon wave

图 9 PISA 法用于(A)单细胞 ${ }^{[140]}$ 和(B)复杂样品 ${ }^{[141]}$ 中蛋白质的检测原 理示意图

Figure 9 Schematic of PISA for the detection of proteins in single cells ${ }^{[140]}$ and complex samples ${ }^{[141]}$

上述研究中使用 MIP 用作靶标蛋白的识别和捕获 同时使用亲和配基修饰的球形纳米颗粒拉曼标签实现 信号增强. 事实上, 拉曼标签还可以使用具有更强增强 效应的其它纳米材料, 如 $\mathrm{Au}$ 纳米星颗粒 ${ }^{[148]}$ 和 $\mathrm{Au} @ \mathrm{Ag}$ 核壳结构纳米结构 ${ }^{[149]}$. 近来, Sales 等 ${ }^{[148]}$ 构建了 MIP 萃 取金基底/目标蛋白/抗体修饰的 $\mathrm{Au}$ 纳米星 SERS 标签的 夹心复合物(图 10A), 实现了对 CEA 的高灵敏检测, 检 测限为 $1.0 \mathrm{ng} / \mathrm{mL}$. 冯尚源等 ${ }^{[149]}$ 构建了分子印迹聚合物 萃取基底/目标蛋白/抗体修饰的 $\mathrm{Au} @ \mathrm{Ag}$ 核壳结构 SERS

A

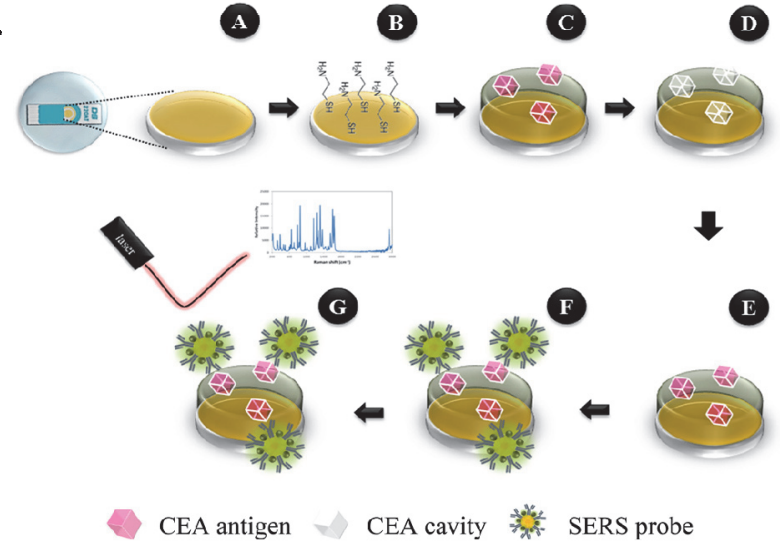

B
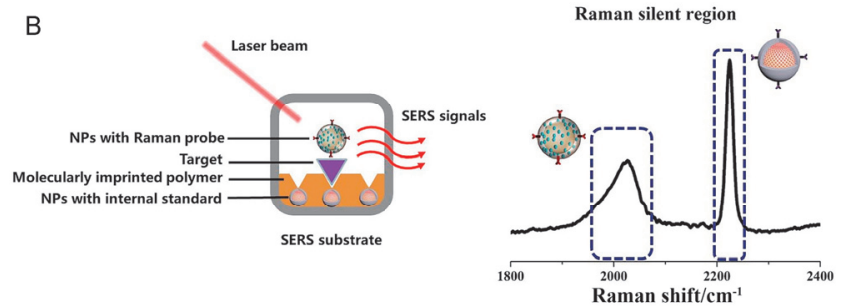

图 10 基于(A) $\mathrm{Au}$ 纳米星 ${ }^{[148]}$ 和(B) $\mathrm{Au} @ \mathrm{Ag}$ 核壳结构的 MIP 和抗体联 用的 SERS 检测原理示意图 ${ }^{[149]}$

Figure 10 Schematic of the combination of MIP and antibodies modified (A) Au nanostar ${ }^{[148]}$ and (B) Au@Ag nanostructure ${ }^{[149]}$ for SERS detection
探针的夹心复合物，如图 $10 \mathrm{~B}$ 所示. 凭借 $\mathrm{C} \equiv \mathrm{C}$ 的拉曼 信号出在静默区 $\left(1800 \sim 2800 \mathrm{~cm}^{-1}\right)$ 的优势，该方法避免 了来自指纹区 $\left(300 \sim 1800 \mathrm{~cm}^{-1}\right)$ 处的内源性分子的光学 噪声. 同时, 以 $\mathrm{C} \equiv \mathrm{N}$ 为内标进行实时校正, 实现了较 高的可重现性检测并最终用于临床血液中 CEA 的检测, 检测限低至 $0.064 \mathrm{pg} / \mathrm{mL}$. 上述方法均是基于 MIP 和抗 体对目标蛋白的识别, 尽管在捕获蛋白方面利用了 MIP 的优势, 但标记时仍依赖抗体识别.

\subsection{2 基于 MIP 的捕获和标记}

除了对完整蛋白进行印迹，通过合理选择蛋白质特 征片段并制备相应的分子印迹材料可在完全不使用抗 体的条件下构建新型免疫分析方法. 基于不同的蛋白质 特征片段，该方法目前可分为两种。一种是基于双重表 位印迹聚合物(duMIP)的 PISA 技术 ${ }^{[102]}$. 原理如图 11 所 示, 以目标蛋白的 $\mathrm{N} 、 \mathrm{C}$ 两端表位作为特征片段，并以 相应的糖化表位为模板分别在 $\mathrm{Au}$ 纳米颗粒自组装单粒 子层和 Ag 基 SERS 纳米标签表面通过嗍亲和针定的定 向表面印迹法制备 MIP, 即可对靶蛋白的两个不同位点 进行双重识别, $\mathrm{Au} @ \mathrm{MIP}$ 纳米颗粒用于捕获蛋白质而 $\mathrm{Ag} @ M I P$ 纳米颗粒用于标记, 该法不仅使专一性得到进 一步提高，还便于构建夹心结构实现高灵敏的等离激元 增强拉曼检测. 以神经元特异性烯醇化酶(NSE)为靶标 疾病标志物，该方法被成功应用于小细胞肺癌病人血清 中 NSE 检测，定量限可达 $10 \mathrm{pg} / \mathrm{mL}$. 第二种是基于正交 双识别 MIP 的 PISA 技术 ${ }^{[150]}$. 不同于前一种技术, 这里 选择了两种不同类型的特征片段(聚糖和表位多肽), 分 别用于识别和标记. 以 CEA 为靶标蛋白, 一方面以 $\mathrm{CEA}$ 的 $\mathrm{N}$ 端糖化表位为模板在 $\mathrm{Au}$ 纳米颗粒自组装单粒 子层上制备识别 CEA 的 MIP; 另一方面, 以 CEA 的 N聚糖为模板在 $\mathrm{Ag}$ 基 SERS 标签上制备 MIP, 从而实现了 基于 MIP 的 N 端表位和 N-聚糖的正交双识别，成功应 用于多种癌症患者血清中 CEA 的检测, 检测限可低至 $5.6 \times 10^{-14} \mathrm{~mol} / \mathrm{L}$. 上述两种方法针对不同类型的蛋白 质疾病标志物的识别与检测提供了新颖的设计思路. 第 一种方法充分考虑到蛋白质本身具有 N、C 两端表位的 结构特性，得益于 MIP 可定制合成的优势，利用糖化表 位即可方便地制备人工抗体对靶标蛋白两端进行识别, 从而构建通用的基于 duMIP 的蛋白质 PISA 检测方法. 第二种方法中，以目标蛋白的糖基化修饰为识别靶点， 在检测蛋白质的同时对其糖基化修饰也进行了确认，因 此利用该方法可进一步通过识别疾病标志物糖基化的 不同从而对疾病进行精准诊断. 相较于传统的 ELISA, 这两种方法完全避免了抗体的使用, 故在稳定性、经济 性及制备方便性等方面展现出更大优势. 尽管如此，抗 体的其它潜在优势, 如尺寸很小(远小于目前 SERS 标 签)、单一位点识别能力强及生物兼容性好等, 对于设计 更合理高效的基于 MIP 和 SERS 的检测方法具有借鉴意 义. 


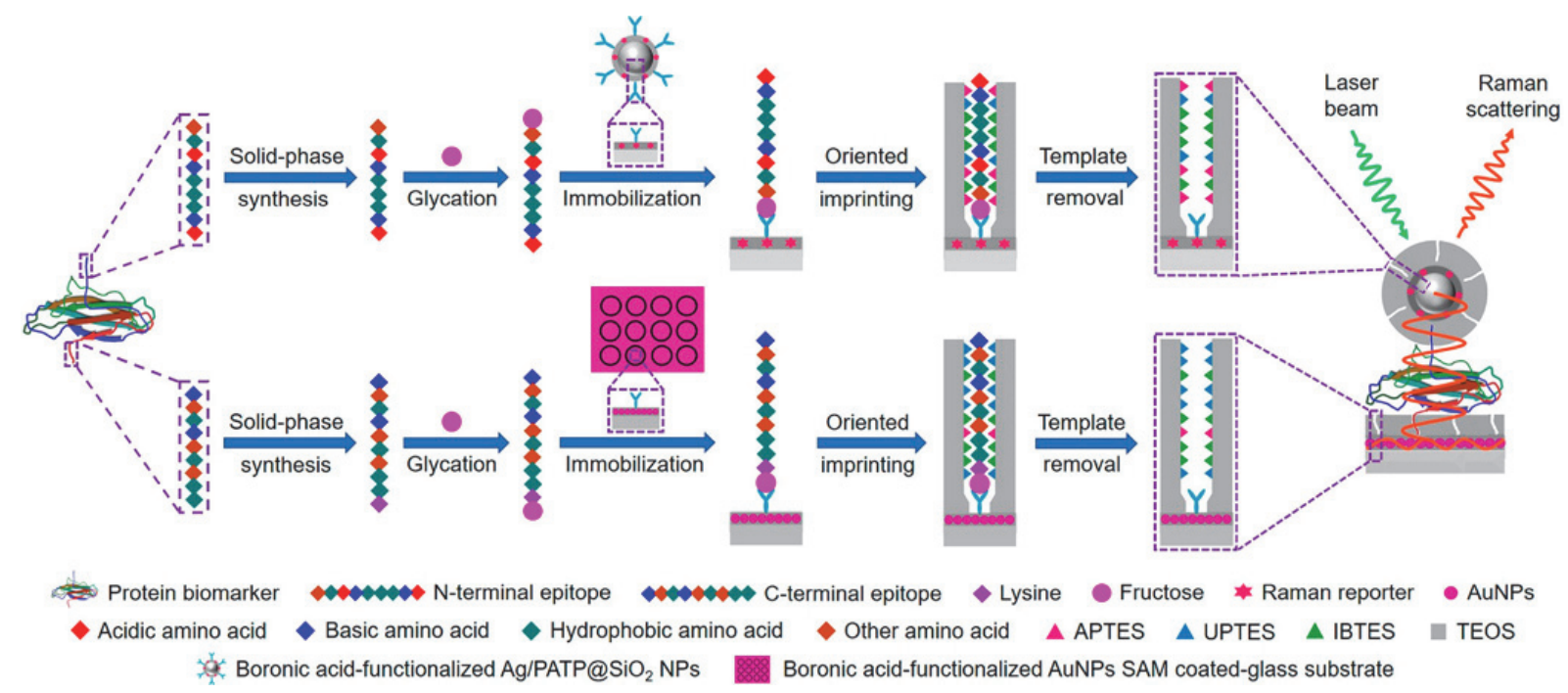

图 11 基于双重表位 MIP 识别的蛋白质间接 SERS 检测原理示意图 ${ }^{[102]}$

Figure 11 Schematic of the duMIP-based indirect SERS detection of target protein ${ }^{[102]}$

\section{2 无标记的检测策略}

无标记的检测策略是将目标蛋白识别后直接利用 SERS 增强其拉曼散射信号从而读取其分子的指纹信息. 然而, 复杂体系中蛋白质的直接 SERS 检测会遇到很强 的基质干扰，导致光谱复杂难以分析. 而 MIP 对蛋白质 的特异性识别可以很好地解决这一问题, 在不引入抗体 或适配体等有可能产生信号干扰的同时专一性增强靶 标蛋白的信号, 因此结合 MIP 和 SERS 的蛋白质直接检 测方法受到关注 ${ }^{[151-155]}$.

谭天伟等 ${ }^{[151]}$ 制备了转铁蛋白(TRF)印迹的金纳米 棒, 在高 $\mathrm{pH}$ 下可以形成聚集体, 将 TRF 专一性地嵌合 到聚集体中, 可实现直接对血清中的 TRF 进行 SERS 高 灵敏检测(检测限为 $10^{-8} \mathrm{~mol} / \mathrm{L}$ ). 如图 $12 \mathrm{~A}$ 所示, 该方法 中由于金纳米棒聚集体的构建, 产生热点, 进而提高了 SERS 无标记检测的灵敏度. 随后, 吕永琴等 ${ }^{[152]}$ 通过在 金纳米棒的表面上合成蛋白质印迹的聚( $\mathrm{N}$-异丙基丙烯 酰胺)自组装单分子层来构建辣根过氧化物酶(HRP)的 高选择性和温敏性的新型等离激元纳米探针, 如图 12B 所示, 通过调节外部温度, 该探针可再生, 并实现了 HRP 的体外高灵敏检测(检测限为 $10^{-14} \mathrm{~mol} / \mathrm{L}$ ) 和表皮生 长因子受体在细胞表面的成像分析. 此外, 也可在二维/ 核-壳结构 SERS 基底材料(Graphene/Ag)表面制备牛血 清白蛋白(BSA)的 MIP, 基于二维材料和 Ag 材料的耦合 作用，可实现高灵敏检测(检测限为 $10^{-12} \mathrm{~mol} / \mathrm{L}$ ) ${ }^{[153]}$.

尽管 MIP-SERS 直接检测蛋白已开展了一些工作, 仍存在一些客观限制条件, 如待检测蛋白本身须具有一 定的拉曼响应, 否则即便通过 SERS 增强也难以实现高 灵敏检测. 对于这一问题, 可以在 MIP 特异性捕获蛋白 后再进行化学修饰以增强其拉曼响应, 同时设计更为高 效的等离激元纳米结构以实现更高的增强效应. 虽然在 这些方面还有诸多需要改进的地方, 但鉴于拉曼光谱可
以反映蛋白的结构特征, 直接 MIP-SERS 检测蛋白仍有 重要的价值.
A

(a)
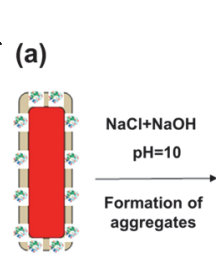

(c)
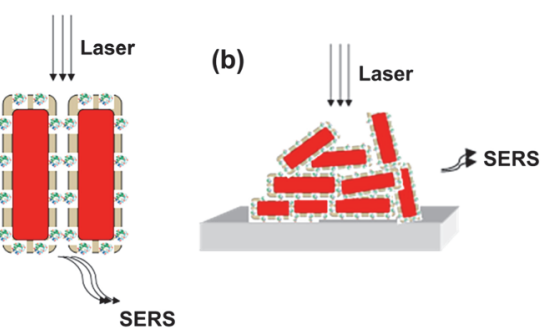

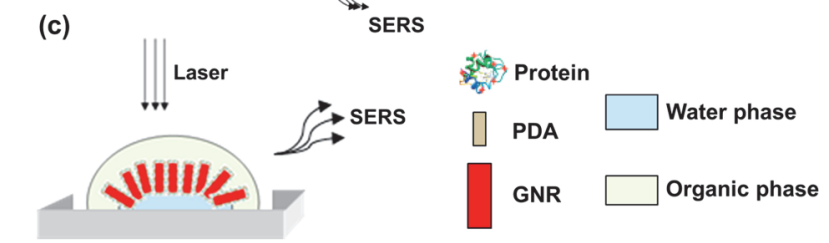

B

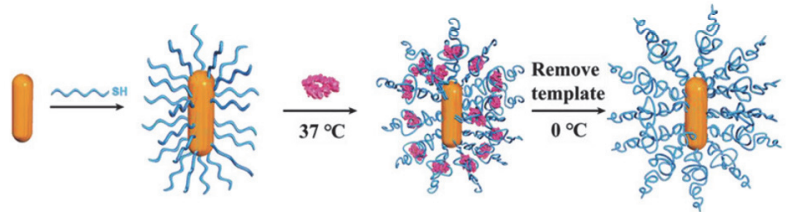

图 12 (A)用于选择性 SERS 检测转铁蛋白的分子印迹等离子体纳米 传感器 ${ }^{[151]}$ 和(B) 覆有印迹层的金纳米棒 SERS 传感器 ${ }^{[152]}$

Figure 12 Overview of (A) molecularly imprinted plasmonic nanosensor for selective SERS detection of transferrin ${ }^{[151]}$ and (B) gold nanorods coated with imprinted layer (MIP@AuNR) SERS sensor ${ }^{[152]}$

\section{3 存在的问题及解决方案}

由于 MIP 对目标蛋白的特异性识别, 无论是对于直 接 SERS 检测还是标记检测均减少了复杂基质所带来的 干扰, 但需要注意的是由于激光器功率不稳定、SERS 活性基底上热点的分布不均和微环境的影响, 多数方法 的可重复性有待改善, 这也是该方法能推广和应用的前 提. 特别是, 目前 SERS 的定量分析仍然具有一定挑战. 然而, 蛋白质疾病标志物的准确定量对于疾病的精准诊 断意义重大, 故亟需发展稳定可重复的可定量检测蛋白 
质的 SERS 技术. 目前已发展出多种 SERS 定量分析方 法. 刘定斌等 ${ }^{[156]}$ 提出了利用 $\mathrm{C} \equiv \mathrm{N}$ 基团在拉曼静默区 $\left(1800 \sim 2800 \mathrm{~cm}^{-1}\right)$ 引入内标, 可有效地消除背景干扰. 王树等 ${ }^{[157]}$ 合成了一种含 $\mathrm{C} \equiv \mathrm{C}$ 三键的聚合物纳米颗粒, 在静默区也产生了较强的信号可作为内标, 降低细胞拉 曼成像时的背景干扰. 田阳等 ${ }^{[158]}$ 将含 $\mathrm{C} \equiv \mathrm{N}$ 基团的报告 分子修饰到微萃取探针上作内参, 实现了脑组织切片或 单个神经元细胞中碳酸根和 $\mathrm{pH}$ 的高重复性定量分析. 除了静默区内标校正, 刘宝红等 ${ }^{[159]}$ 报道了一种按需定 量 SERS 检测技术, 该方法利用了氧化酶催化反应副产 物 $\mathrm{H}_{2} \mathrm{O}_{2}$ 可将 $\mathrm{Au}$ 纳米颗粒表面修饰的报告分子颈基苯㸴 酸氧化为放基苯酚从而产生一个新的拉曼谱峰, 与原来 的谱峰强度进行比率分析, 有效地降低了信号波动, 可 用于稳定可靠的小分子代谢物定量分析. 钱昆等 ${ }^{[160]}$ 进 一步将该反应构建于大孔有序二氧化硅泡沫结构中形 成纳米反应器, 实现了低样品损耗的超灵敏定量分析检 测. 此外, 根据报告分子对信号的相应不同也可以构建 比率检测，李聪等 ${ }^{[161]}$ 在 $\mathrm{Au}$ 纳米星表面同时修饰一种 $\mathrm{pH}$ 响应的标签和一种无 $\mathrm{pH}$ 响应的标签, 两种标签的信 号比可以稳定地反映环境 $\mathrm{pH}$ 的变化. 同时基底材料尺 寸均一性、表面修饰性及抗干扰能力等也是设计和改进 该类方法的关键. 上述方案均可用于今后 MIP-SERS 定 量分析蛋白疾病标志物.

综上所述, MIP-SERS 联用技术展现出了巨大的优 势. 尽管目前临床检测中有少数基于抗体的测试成本已 降低, 但对于具有重要临床诊断价值的疾病标志物蛋白 的检测成本仍然较高, 尤其是针对具体的疾病诊断/分 型可能需要基于几个甚至十几个标志物的同时评测才 能确诊, 因此 MIP 在稳定性和成本方面仍具有明显的优 势. 另外, 也存在一些抗体难制备的情况, 例如 AFP 检 测虽然可以用抗体但依据 AFP 的疾病分型依赖凝集素 检测聚糖的不同, 而凝集素的交叉反应性较高, 结果准 确率降低; CA19-9 抗原实际是一段糖, 其免疫源性差抗 体难制备; 病毒表面抗原暴露有限, 难以制备抗体. 对 于上述这些情况，通过分子印迹技术均可以方便地制备 相应的印迹材料作为 “人工抗体” 用于特异性的识别这 些 “抗原” . 另一方面, SERS 技术用更小的样品体积即 可实现超灵敏的检测, 如目前临床方法通常需要几毫升 血液的检测, 利用 SERS 技术仅需要几微升的样品即可 实现检测; 同时, 拉曼光谱可用于多种不同形态样品, 除了常规检测用的血液、尿液等生物液体, 其它诸如呼 吸气体或直接在皮肤/组织表面检测等也可通过 SERS 检测. 因此, MIP-SERS 联用方法在临床检测领域的价 值有待进一步发掘.

\section{5 总结与展望}

随着人们对生命健康的关注和要求不断提高, 对疾 病的诊疗需求也不断增长. 基于蛋白质疾病标志物的早
期诊断可以为早期治疗提供依据，以晠少病患痛苦和疾 病相关的负担. 面对传统临床检测中复杂的基质干扰和 疾病标志物蛋白丰度低的问题，检测方法的专一性和灵 敏度仍需要不断提高. 更重要的是, 针对目前免疫分析 难以解决的问题, 如针对某些重要标志物的抗体难制 备、光谱信息单一且难以提供分子指纹信息等，基于 MIP 和 SERS 联用的新型蛋白质检测技术可提供更好的 解决方案, 但仍未达到可替代免疫分析的水平, 还需要 深入的发展. 对于 MIP 而言, 提高专一性和亲和力、降 低交叉反应性、实现精准识别仍是当前和今后需要努力 的方向. 对于 SERS 而言，更稳定信号增强、更合理的 纳米结构设计及更匹配临床诊断需求的分析方法有待 发展. 在联用方面, 如何通过更合理的设计实现 MIP 和 SERS 的进一步优势互补, 实现专一性和灵敏度的双提 升仍有待探索, 其中如何制备稳定的、具有抗体尺寸和 性能的 MIP 修饰的 SERS 纳米标签是该技术发展的关 键. 此外, 鉴于拉曼光谱仪已实现微型化和便携化但适 用于疾病诊断的拉曼光谱仪器还未出现, 设计更稳定高 效的 MIP 和 SERS 组合形式及适用于快检的装置和试剂 用于蛋白质标志物的床旁治疗(POC)值得关注.

\section{作者简介}

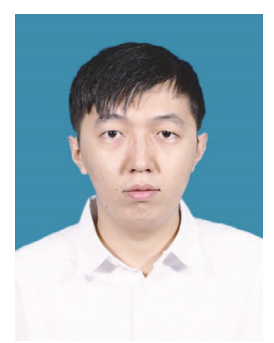

贺晖, 2012 年本科毕业于西北农林科技大学, 2015 年硕士 毕业于西北农林科技大学, 2019 年博士毕业于南京大学化学 化工学院, 取得博士学位后留校工作任副研究员. 主要研究 方向为等离激元增强效应研究、生物分子质谱分析及单细胞 分析.

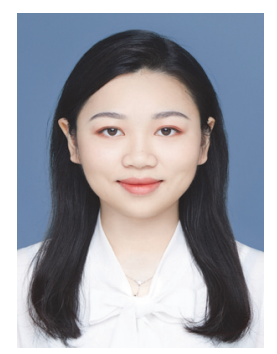

周玲俐, 2017 年本科毕业于郑州大学化学与分子工程学 院, 2020 年硕士毕业于南京大学化学化工学院, 主要从事基于 分子印迹聚合物和表面增强拉曼光谱的蛋白质检测方向的研 究. 


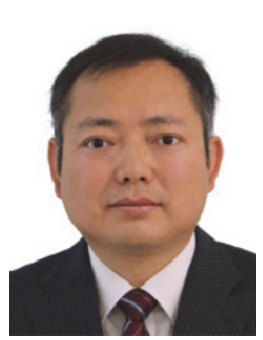

刘震, 1998 年于中国科学院大连化学物理研究所获博士 学位. $2000 \sim 2002$ 年, 日本兵库大学日本学术振兴会(JSPS)特 别研究员; 2002 2005 年, 加拿大滑铁卢大学博士后. 2005 年 获聘南京大学教授, 2006 年起任博士生导师, 2011 2014 年任 加拿大滑铁卢大学工程学院兼职教授, 2014 年获国家杰出青 年科学基金. 主要研究方向: 以仿生分子识别为核心, 结合纳 米技术、先进材料、分离科学、生物质谱和拉曼光谱等手段, 发 展生物分离、组学分析、疾病诊断分析、单细胞分析、癌症 靶向及免疫治疗新方法和新材料.

\section{References}

[1] Sawyers, C. L. Nature 2008, 452, 548.

[2] Tentler, J. J.; Tan, A. C.; Weekes, C. D.; Jimeno, A.; Leong, S.; Pitts, T. M.; Arcaroli, J. J.; Messersmith, W. A.; Eckhardt, S. G. Nat. Rev. Clin. Onco. 2012, 9, 338

[3] Schwarzenbach, H.; Nishida, N.; Calin, G. A.; Pantel, K. Nat. Rev. Clin. Onco. 2014, $11,145$.

[4] Schumacher, T. N.; Schreiber, R. D. Science 2015, 348, 69.

[5] Topalian, S. L.; Taube, J. M.; Anders, R. A.; Pardoll, D. M. Nat. Rev. Cancer 2016, 16, 275.

[6] Zhang, J.; Liu, H.; Meng, L. Chinese J. Org. Chem. 2019, 39, 3132 (in Chinese). (张继东, 刘鸿泽, 孟丽, 有机化学, 2019, 39, 3132.)

[7] Wulfkuhle, J. D.; Liotta, L. A.; Petricoin, E. F. Nat. Rev. Cancer 2003, 3, 267.

[8] Morin, P. J. Cancer Res. 2005, 65, 9603.

[9] Wu, L.; Qu, X. G. Chem. Soc. Rev. 2015, 44, 2963.

[10] Song, Y.; Wei, W.; Qu, X. Adv. Mater. 2011, 23, 4215.

[11] Wang, X.; Wang, C.; Qu, K.; Song, Y.; Ren, J.; Miyoshi, D.; Sugimoto, N.; Qu, X. Adv. Funct. Mater. 2010, 20, 3967.

[12] Chaubard, J. L.; Krishnamurthy, C.; Yi, W.; Smith, D. F.; Hsieh-Wilson, L. C. J. Am. Chem. Soc. 2012, 134, 4489.

[13] Fan, L.; Jiang, Q.; Pan, M.; Wang, W.; Zhang, L.; Liu, X. Acta Chim. Sinica 2020, 78, 419 (in Chinese). (樊蕾, 江群英, 潘敏, 王文晓, 张丽, 刘晓庆, 化学学报, 2020, 78, 419.)

[14] He, L. L.; Rodda, T.; Haynes, C. L.; Deschaines, T.; Strother, T.; Diez-Gonzalez, F.; Labuza, T. P. Anal. Chem. 2011, 83, 1510.

[15] Wang, Z. Y.; Zong, S. F.; Li, W.; Wang, C. L.; Xu, S. H.; Chen, H.; Cui, Y. P. J. Am. Chem. Soc. 2012, 134, 2993.

[16] Lee, M.; Lee, K.; Kim, K. H.; Oh, K. W.; Choo, J. Lab Chip 2012, 12,3720 .

[17] Li, M.; Kang, J. W.; Sukumar, S.; Dasari, R. R.; Barman, I. Chem. Sci. 2015, 6, 3906

[18] Li, J.; Dong, S. J.; Tong, J. J.; Zhu, P. Z.; Diao, G. W.; Yang, Z. J. Chem. Commun. 2016, 52, 284.

[19] Xiao, F.-N.; Wang, M.; Wang, F.-B.; Xia, X.-H. Small 2014, 10, 706.

[20] Munge, B. S.; Coffey, A. L.; Doucette, J. M.; Somba, B. K.; Malhotra, R.; Patel, V.; Gutkind, J. S.; Rusling, J. F. Angew. Chem. Int. Ed. 2011, 50, 7915 .

[21] Prats-Alfonso, E.; Sisquella, X.; Zine, N.; Gabriel, G.; Guimera, A.; Javier del Campo, F.; Villa, R.; Eisenberg, A. H.; Mrksich, M.; Errachid, A.; Aguilo, J.; Albericio, F. Small 2012, 8, 2106.

[22] de la Escosura-Muniz, A.; Merkoci, A. Small 2011, 7, 675.

[23] Wang, S.; Haque, F.; Rychahou, P. G.; Evers, B. M.; Guo, P. ACS Nano 2013, 7, 9814.

[24] Thomas, J. M.; Chakraborty, B.; Sen, D.; Yu, H.-Z. J. Am. Chem. Soc. 2012, 134, 13823.

[25] Yang, H.-W.; Lin, C.-W.; Hua, M.-Y.; Liao, S.-S.; Chen, Y.-T.; Chen, H.-C.; Weng, W.-H.; Chuang, C.-K.; Pang, S.-T.; Ma, C.-C. M. Adv. Mater 2014, 26, 3662.

[26] Lai, G.; Wu, J.; Ju, H.; Yan, F. Adv. Funct. Mater. 2011, 21, 2938.

[27] Diamandis, E. P. Mol. Cell. Proteomics 2004, 3, 367.
[28] Clark, M. F.; Adams, A. N. J. Gen. Virol. 1977, 34, 475.

[29] Engvall, E.; Perlmann, P. Immunochemistry 1971, 8, 871.

[30] Reen, D. J. Methods Mol. Biol. 1994, 32, 461.

[31] Zheng, G. F.; Patolsky, F.; Cui, Y.; Wang, W. U.; Lieber, C. M. Nat. Biotechnol. 2005, 23, 1294.

[32] Xu, J. J.; Haupt, K.; Bui, B. T. S. ACS Appl. Mater. Interfaces 2017, 9, 24476

[33] Chianella, I.; Guerreiro, A.; Moczko, E.; Caygill, J. S.; Piletska, E. V.; Sansalvador, I. M. P. D. V.; Whitcombe, M. J.; Piletsky, S. A. Anal. Chem. 2013, 85, 8462.

[34] Li, L.; Lu, Y.; Bie, Z. J.; Chen, H. Y.; Liu, Z. Angew. Chem. Int. Ed. 2013, 52, 7451

[35] Sun, X.; Jian, Y.; Wang, H.; Ge, S.; Yan, M.; Yu, J. ACS Appl. Mater. Interfaces 2019, 11, 16198.

[36] Schlucker, S. Angew. Chem. Int. Ed. 2014, 53, 4756

[37] Grubisha, D. S.; Lipert, R. J.; Park, H. Y.; Driskell, J.; Porter, M. D. Anal. Chem. 2003, 75, 5936.

[38] Bantz, K. C.; Meyer, A. F.; Wittenberg, N. J.; Im, H.; Kurtulus, O.; Lee, S. H.; Lindquist, N. C.; Oh, S.-H.; Haynes, C. L. Phys. Chem. Chem. Phys. 2011, 13, 11551.

[39] Nie, S.; Emory, S. R. Science 1997, 275, 1102.

[40] Wackerlig, J.; Lieberzeit, P. A. Sensor. Actuat. B-Chem. 2015, 207, 144.

[41] Szlag, V. M.; Rodriguez, R. S.; He, J. Y.; Hudson-Smith, N.; Kang, H.; Le, N.; Reineke, T. M.; Haynes, C. L. ACS Appl. Mater. Interfaces 2018, 10, 31825.

[42] Guo, X. T.; Li, J. H.; Arabi, M.; Wang, X. Y.; Wang, Y. Q.; Chen, L. X. ACS Sensors 2020, 5, 601 .

[43] Wulff, G.; Liu, J. Q. Acc. Chem. Res. 2012, 45, 239.

[44] Chen, L. X.; Wang, X. Y.; Lu, W. H.; Wu, X. Q.; Li, J. H. Chem. Soc. Rev. 2016, 45, 2137

[45] BelBruno, J. J. Chem. Rev. 2019, 119, 94.

[46] Xing, R.; Wen, Y.; He, H.; Guo, Z.; Liu, Z. TrAC-Trend Anal. Chem 2019, 110, 417.

[47] Pan, J. M.; Chen, W.; Ma, Y.; Pan, G. Q. Chem. Soc. Rev. 2018, 47, 5574.

[48] Wang, S. S.; Wen, Y. R.; Wang, Y. J.; Ma, Y. Y.; Liu, Z. Anal. Chem. 2017, 89, 5646.

[49] Yin, D. Y.; Li, X. L.; Ma, Y. Y.; Liu, Z. Chem. Commun. 2017, 53, 6716.

[50] Dong, Y. R.; Li, W.; Gu, Z. K.; Xing, R. R.; Ma, Y. Y.; Zhang, Q.; Liu, Z. Angew. Chem. Int. Ed. 2019, 58, 10621.

[51] Whitcombe, M. J.; Chianella, I.; Larcombe, L.; Piletsky, S. A.; Noble, J.; Porter, R.; Horgan, A. Chem. Soc. Rev. 2011, 40, 1547.

[52] Liu, Z.; He, H. Acc. Chem. Res. 2017, 50, 2185.

[53] Zhang, H. Adv. Mater. 2020, 32, 1806328.

[54] Yang, K.; Li, S.; Liu, L.; Chen, Y.; Zhou, W.; Pei, J.; Liang, Z.; Zhang, L.; Zhang, Y. Adv. Mater. 2019, 31, 1902048.

[55] Ge, Y.; Turner, A. Trends Biotechnol. 2008, 26, 218.

[56] Shi, H.; Tsai, W.; Garrison, M. D.; Ferrari, S.; Ratner, B. D. Nature 1999, 398, 593

[57] Gao, D.; Zhang, Z.; Wu, M.; Xie, C.; Guan, G.; Wang, D. J. Am Chem. Soc. 2007, 129, 7859.

[58] Poma, A.; Guerreiro, A.; Whitcombe, M. J.; Piletska, E. V.; Turner, A. P.; Piletsky, S. A. Adv. Funct. Mater. 2013, 23, 2821.

[59] Canfarotta, F.; Poma, A.; Guerreiro, A.; Piletsky, S. Nat. Protoc. 2016, 11,443 .

[60] Daoud Attieh, M.; Zhao, Y.; Elkak, A.; Falcimaigne-Cordin, A.; Haupt, K. Angew. Chem. Int. Ed. 2017, 56, 3339.

[61] Mahajan, R.; Rouhi, M.; Shinde, S.; Bedwell, T. S.; Incel, A.; Mavliutova, L.; Piletsky, S. A.; Nicholls, I. A.; Sellergren, B. Angew. Chem. Int. Ed. 2019, 58, 727.

[62] Shen, X.; Ye, L. Chem. Commun. 2011, 47, 10359

[63] Shen, X.; Zhou, T.; Ye, L. Chem. Commun. 2012, 48, 8198

[64] Shen, X.; Bonde, J. S.; Kamra, T.; Bulow, L.; Leo, J. C.; Linke, D.; Ye, L. Angew. Chem. Int. Ed. 2014, 53, 10687.

[65] Wang, S.; Ye, J.; Bie, Z.; Liu, Z. Chem. Sci. 2014, 5, 1135.

[66] Bi, X. D.; Liu, Z. Anal. Chem. 2014, 86, 12382.

[67] Bi, X. D.; Liu, Z. Anal. Chem. 2014, 86, 959.

[68] Moremen, K. W.; Tiemeyer, M.; Nairn, A. V. Nat. Rev. Mol. Cell Biol. 2012, 13, 448 .

[69] Xiong, Y.; Chen, Y.; Ju, H. Acta Chim. Sinica 2019, 77, 1221 (in Chinese). (熊莹莹, 陈云龙, 鞠熀先, 化学学报, 2019, 77, 1221.)

[70] Bie, Z.; Chen, Y.; Ye, J.; Wang, S.; Liu, Z. Angew. Chem. Int. Ed. 2015, 54, 10211

[71] Bie, Z.; Xing, R.; He, X.; Ma, Y.; Chen, Y.; Liu, Z. Anal. Chem. 
2018, 90, 9845.

[72] Xing, R.; Wang, S.; Bie, Z.; He, H.; Liu, Z. Nat. Protoc. 2017, 12, 964.

[73] Yin, D. Y.; Wang, S. S.; He, Y. J.; Liu, J.; Zhou, M.; Ouyang, J.; Liu, B. R.; Chen, H. Y.; Liu, Z. Chem. Commun. 2015, 51, 17696.

[74] Chen, Y.; Li, X. L.; Yin, D. Y.; Li, D. J.; Bie, Z. J.; Liu, Z. Chem. Commun. 2015, 51, 10929.

[75] He, H.; Muhammad, P.; Guo, Z. C.; Peng, Q. L.; Lu, H. F.; Liu, Z. Biosens. Bioelectron. 2019, 146, 10.

[76] Pearce, O. M.; Laubli, H. Glycobiology 2016, 26, 111.

[77] Shinde, S.; El-Schich, Z.; Malakpour, A.; Wan, W.; Dizeyi, N.; Mohammadi, R.; Rurack, K.; Gjorloff Wingren, A.; Sellergren, B. J. Am. Chem. Soc. 2015, 137, 13908.

[78] Panagiotopoulou, M.; Salinas, Y.; Beyazit, S.; Kunath, S.; Duma, L.; Prost, E.; Mayes, A. G.; Resmini, M.; Tse Sum Bui, B.; Haupt, K. Angew. Chem. Int. Ed. 2016, 55, 8244.

[79] Wang, S.; Yin, D.; Wang, W.; Shen, X.; Zhu, J. J.; Chen, H. Y.; Liu, Z. Sci. Rep. 2016, 6, 22757.

[80] Gu, Z.; Dong, Y.; Xu, S.; Wang, L.; Liu, Z. Angew. Chem. Int. Ed. 2020. DOI: 10.1002/anie. 202012956

[81] Nishino, H.; Huang, C.-S.; Shea, K. J. Angew. Chem. Int. Ed. 2006, $45,2392$.

[82] Hoshino, Y.; Kodama, T.; Okahata, Y.; Shea, K. J. J. Am. Chem. Soc. 2008, 130, 15242.

[83] Zeng, Z.; Patel, J.; Lee, S. H.; McCallum, M.; Tyagi, A.; Yan, M.; Shea, K. J. J. Am. Chem. Soc. 2012, 134, 2681.

[84] Yoshimatsu, K.; Koide, H.; Hoshino, Y.; Shea, K. J. Nat. Protoc. 2015, 10, 595 .

[85] Liu, M.; Huang, R.; Weisman, A.; Yu, X.; Lee, S. H.; Chen, Y.; Huang, C.; Hu, S.; Chen, X.; Tan, W.; Liu, F.; Chen, H.; Shea, K. J. J. Am. Chem. Soc. 2018, 140, 6853 .

[86] Titirici, M. M.; Hall, A. J.; Sellergren, B. Chem. Mater. 2003, 15, 822.

[87] Pan, G.; Shinde, S.; Yeung, S. Y.; Jakštaite, M.; Li, Q.; Wingren, A. G.; Sellergren, B. Angew. Chem. Int. Ed. 2017, 56, 15959.

[88] Urraca, J. L.; Aureliano, C. S.; Schillinger, E.; Esselmann, H.; Wiltfang, J.; Sellergren, B. J. Am. Chem. Soc. 2011, 133, 9220.

[89] Canfarotta, F.; Lezina, L.; Guerreiro, A.; Czulak, J.; Petukhov, A.; Daks, A.; Smolinska-Kempisty, K.; Poma, A.; Piletsky, S.; Barlev, N. A. Nano Lett. 2018, 18, 4641.

[90] Medina Rangel, P. X.; Moroni, E.; Merlier, F.; Gheber, L. A.; Vago, R.; Tse Sum Bui, B.; Haupt, K. Angew. Chem. Int. Ed. 2020, 59, 2816.

[91] Pan, G.; Guo, Q.; Ma, Y.; Yang, H.; Li, B. Angew. Chem. Int. Ed. 2013, 52, 6907.

[92] Qin, Y. T.; Peng, H.; He, X. W.; Li, W. Y.; Zhang, Y. K. Anal. Chem. 2019, 91, 12696.

[93] Peng, H.; Qin, Y. T.; He, X. W.; Li, W. Y.; Zhang, Y. K. ACS Appl. Mater. Interfaces 2020, 12, 13360.

[94] Yang, K.; Liu, J.; Li, S.; Li, Q.; Wu, Q.; Zhou, Y.; Zhao, Q.; Deng, N.; Liang, Z.; Zhang, L.; Zhang, Y. Chem. Commun. 2014, 50, 9521.

[95] Yang, K.; Li, S.; Liu, J.; Liu, L.; Zhang, L.; Zhang, Y. Anal. Chem. 2016, $88,5621$.

[96] Hoshino, Y.; Koide, H.; Urakami, T.; Kanazawa, H.; Kodama, T.; Oku, N.; Shea, K. J. J. Am. Chem. Soc. 2010, 132, 6644.

[97] Dechtrirat, D.; Jetzschmann, K. J.; Stöcklein, W. F. M.; Scheller, F. W.; Gajovic-Eichelmann, N. Adv. Funct. Mater. 2012, 22, 5231.

[98] Yang, Y. Q.; He, X. W.; Wang, Y. Z.; Li, W. Y.; Zhang, Y. K. Biosens. Bioelectron. 2014, 54, 266.

[99] Lu, C. H.; Zhang, Y.; Tang, S. F.; Fang, Z. B.; Yang, H. H.; Chen, X.; Chen, G. N. Biosens. Bioelectron. 2012, 31, 439.

[100] Xing, R.; Ma, Y.; Wang, Y.; Wen, Y.; Liu, Z. Chem. Sci. 2019, 10, 1831.

[101] Li, D. J.; Chen, Y.; Liu, Z. Chem. Soc. Rev. 2015, 44, 8097.

[102] Xing, R.; Wen, Y.; Dong, Y.; Wang, Y.; Zhang, Q.; Liu, Z. Anal. Chem. 2019, 91, 9993.

[103] Crapnell, R. D.; Canfarotta, F.; Czulak, J.; Johnson, R.; Betlem, K.; Mecozzi, F.; Down, M. P.; Eersels, K.; van Grinsven, B.; Cleij, T. J.; Law, R.; Banks, C. E.; Peeters, M. ACS Sensors 2019, 4, 2838.

[104] Baldoneschi, V.; Palladino, P.; Banchini, M.; Minunni, M.; Scarano, S. Biosens. Bioelectron. 2020, 157, 112161.

[105] Yan, Y.-J.; He, X.-W.; Li, W.-Y.; Zhang, Y.-K. Biosens. Bioelectron. 2017, 91, 253.

[106] Li, D.-Y.; Zhang, X.-M.; Yan, Y.-J.; He, X.-W.; Li, W.-Y.; Zhang, Y.-K. Biosens. Bioelectron. 2016, 79, 187.
[107] Tchinda, R.; Tutsch, A.; Schmid, B.; Sussmuth, R. D.; Altintas, Z. Biosens. Bioelectron. 2019, 123, 260.

[108] Karimian, N.; Vagin, M.; Zavar, M. H. A.; Chamsaz, M.; Turner, A. P. F.; Tiwari, A. Biosens. Bioelectron. 2013, 50, 492.

[109] Moreira, F. T. C.; Dutra, R. A. F.; Noronha, J. P. C.; Cunha, A. L.; Sales, M. G. F. Biosens. Bioelectron. 2011, 28, 243.

[110] Ribeiro, J. A.; Pereira, C. M.; Silva, A. F.; Sales, M. G. F. Biosens. Bioelectron. 2018, 109, 246.

[111] Sun, B. H.; Ni, X. J.; Cao, Y. H.; Cao, G. Q. Biosens. Bioelectron. 2017, 91, 354.

[112] You, M.; Yang, S.; Tang, W.; Zhang, F.; He, P.-G. ACS Appl. Mater. Interfaces 2017, 9, 13855.

[113] Campion, A.; Kambhampati, P. Chem. Soc. Rev. 1998, 27, 241.

[114] McFarland, A. D.; Young, M. A.; Dieringer, J. A.; Van Duyne, R. P. J. Phys. Chem. B 2005, 109, 11279.

[115] Kneipp, K.; Kneipp, H.; Kneipp, J. Acc. Chem. Res. 2006, 39, 443.

[116] Stiles, P. L.; Dieringer, J. A.; Shah, N. C.; Van Duyne, R. R. Annu. Rev. Anal. Chem. 2008, 1, 601.

[117] Lee, H. K.; Lee, Y. H.; Koh, C. S. L.; Phan-Quang, G. C.; Han, X.; Lay, C. L.; Sim, H. Y. F.; Kao, Y. C.; An, Q.; Ling, X. Y. Chem. Soc. Rev. 2019, 48, 731.

[118] Lane, L. A.; Qian, X. M.; Nie, S. M. Chem. Rev. 2015, 115, 10489.

[119] Nam, J.-M.; Oh, J.-W.; Lee, H.; Suh, Y. D. Acc. Chem. Res. 2016, 49, 2746.

[120] Ding, S. Y.; Yi, J.; Li, J. F.; Ren, B.; Wu, D. Y.; Panneerselvam, R.; Tian, Z. Q. Nat. Rev. Mater. 2016, 1, 16021

[121] Zrimsek, A. B.; Chiang, N.; Mattei, M.; Zaleski, S.; McAnally, M. O.; Chapman, C. T.; Henry, A.-I.; Schatz, G. C.; Van Duyne, R. P. Chem. Rev. 2016, 117, 7583.

[122] Li, J. F.; Zhang, Y. J.; Ding, S. Y.; Panneerselvam, R.; Tian, Z. Q. Chem. Rev. 2017, 117, 5002.

[123] Zong, C.; Xu, M.; Xu, L.-J.; Wei, T.; Ma, X.; Zheng, X.-S.; Hu, R.; Ren, B. Chem. Rev. 2018, 118, 4946.

[124] Xu, L.-J.; Zong, C.; Zheng, X.-S.; Hu, P.; Feng, J.-M.; Ren, B. Anal. Chem. 2014, 86, 2238.

[125] Wackerbarth, H.; Klar, U.; Gunther, W.; Hildebrandt, P. Appl. Spectrosc. 1999, 53, 283.

[126] Soldatova, A. V.; Ibrahim, M.; Olson, J. S.; Czernuszewicz, R. S.; Spiro, T. G. J. Am. Chem. Soc. 2010, 132, 4614.

[127] Feng, M. L.; Tachikawa, H. J. Am. Chem. Soc. 2008, 130, 7443.

[128] Matteini, P.; Cottat, M.; Tavanti, F.; Panfilova, E.; Scuderi, M.; Nicotra, G.; Menziani, M. C.; Khlebtsov, N.; de Angelis, M.; Pini, R. ACS Nano 2017, 11, 918.

[129] Xu, H. X.; Bjerneld, E. J.; Kall, M.; Borjesson, L. Phys. Rev. Lett. 1999, 83, 4357.

[130] Zhang, H.; Kou, Y.; Li, J.; Chen, L.; Mao, Z.; Han, X. X.; Zhao, B.; Ozaki, Y. Anal. Chem. 2019, 91, 1213.

[131] Bai, X.-R.; Wang, L.-H.; Ren, J.-Q.; Bai, X.-W.; Zeng, L.-W.; Shen, A.-G.; Hu, J.-M. Anal. Chem. 2019, 91, 2955.

[132] Su, Y.; Wu, D.; Chen, J.; Chen, G.; Hu, N.; Wang, H.; Wang, P.; Han, H.; Li, G.; Wut, Y. Anal. Chem. 2019, 91, 11687.

[133] Wang, J. R.; Xia, C.; Yang, L.; Li, Y. F.; Li, C. M.; Huang, C. Z. Anal. Chem. 2020, 92, 4046.

[134] Chen, Z.; Tabakman, S. M.; Goodwin, A. P.; Kattah, M. G.; Daranciang, D.; Wang, X.; Zhang, G.; Li, X.; Liu, Z.; Utz, P. J.; Jiang, K.; Fan, S.; Dai, H. Nat. Biotechnol. 2008, 26, 1285.

[135] Grubisha, D. S.; Lipert, R. J.; Park, H.-Y.; Driskell, J.; Porter, M. D. Anal. Chem. 2003, 75, 5936.

[136] Qi, G.; Li, H.; Zhang, Y.; Li, C.; Xu, S.; Wang, M.; Jin, Y. Anal. Chem. 2019, 91, 1408 .

[137] Cheng, Z.; Choi, N.; Wang, R.; Lee, S.; Moon, K. C.; Yoon, S.-Y.; Chen, L.; Choo, J. ACS Nano 2017, 11, 4926.

[138] Ye, J.; Chen, Y.; Liu, Z. Angew. Chem. Int. Ed. 2014, 53, 10386.

[139] Feng, J.; Li, X.; Cheng, H.; Huang, W.; Kong, H.; Li, Y.; Li, L. Microchim. Acta 2019, 186, 774.

[140] Liu, J.; Yin, D. Y.; Wang, S. S.; Chen, H. Y.; Liu, Z. Angew. Chem. Int. Ed. 2016, 55, 13215.

[141] Tu, X. Y.; Muhammad, P.; Liu, J.; Ma, Y. Y.; Wang, S. S.; Yin, D. Y.; Liug, Z. Anal. Chem. 2016, 88, 12363.

[142] Muhammad, P.; Tu, X. Y.; Liu, J.; Wang, Y. J.; Liu, Z. ACS Appl. Mater. Interfaces 2017, 9, 12082.

[143] Li, W.; Zhang, Q.; Wang, Y. J.; Ma, Y. Y.; Guo, Z. C.; Liu, Z. Anal. Chem. 2019, 91, 4831.

[144] Muhammad, P.; Liu, J.; Xing, R.; Wen, Y.; Wang, Y.; Liu, Z. Anal. Chim. Acta 2017, 995, 34. 
[145] Liu, J.; Wen, Y.; He, H.; Chen, H.-Y.; Liu, Z. Chem. Sci. 2018, 9 , 7241.

[146] Zhang, Q.; Liu, J.; Dong, Y.; Li, W.; Xing, R.; Ma, Y.; Liu, Z. ACS Appl. Nano Mater. 2019, 2, 3960.

[147] Ma, Y.; Li, X.; Liu, J.; Li, W.; Liu, Z. ACS Sensors 2020, 5, 1436.

[148] Carneiro, M. C. C. G.; Sousa-Castillo, A.; Correa-Duarte, M. A.; Sales, M. G. F. Biosens. Bioelectron. 2019, 146, 111761.

[149] Lin, X. L.; Wang, Y. Y.; Wang, L. N.; Lu, Y. D.; Li, J.; Lu, D. C.; Zhou, T.; Huang, Z. F.; Huang, J.; Huang, H. F.; Qiu, S. F.; Chen, R.; Lin, D.; Feng, S. Y. Biosens. Bioelectron. 2019, 143, 10.

[150] Zhou, L.; Wang, Y.; Xing, R.; Chen, J.; Liu, J.; Li, W.; Liu, Z. Biosens. Bioelectron. 2019, 145, 111729.

[151] Lv, Y. Q.; Qin, Y. T.; Svec, F.; Tan, T. W. Biosens. Bioelectron. 2016, $80,433$.

[152] Zhang, T.; Qin, Y. T.; Tan, T. W.; Lv, Y. Q. Part. Part. Syst. Charact. 2018, 35, 10 .

[153] Su, K.; Zhang, Y.; Chen, S.; Zuo, S.; Ha, Y.; Dan, J.; Chen, W.; Sun, C.; Dai, Z.; Shi, X. Appl. Surf. Sci. 2019, 492, 108.
[154] Chen, S. N.; Dong, L. J.; Yan, M.; Dai, Z. X.; Sun, C. H.; Li, X. R. Soc. Open Sci. 2018, 5, 9.

[155] Ren, X.; Yang, L.; Li, Y.; Cheshari, E. C.; Li, X. Spectrochim. Acta A 2020, 228, 117764

[156] Li, M.; Li, J.; Di, H.; Liu, H.; Liu, D. Anal. Chem. 2017, 89, 3532.

[157] Li, S.; Chen, T.; Wang, Y.; Liu, L.; Lv, F.; Li, Z.; Huang, Y.; Schanze, K. S.; Wang, S. Angew. Chem. Int. Ed. 2017, 56, 13455.

[158] Wang, W.; Zhao, F.; Li, M.; Zhang, C.; Shao, Y.; Tian, Y. Angew. Chem. Int. Ed. 2019, 58, 5256.

[159] Zhang, K.; Wang, Y.; Wu, M.; Liu, Y.; Shi, D.; Liu, B. Chem. Sci. 2018, $9,8089$.

[160] Liu, J.; Cai, C.; Wang, Y.; Liu, Y.; Huang, L.; Tian, T.; Yao, Y.; Wei, J.; Chen, R.; Zhang, K.; Liu, B.; Qian, K. Adv. Sci. 2020, 7, 1903730.

[161] Duan, W.; Yue, Q.; Liu, Y.; Zhang, Y.; Guo, Q.; Wang, C.; Yin, S.; Fan, D.; Xu, W.; Zhuang, J.; Gong, J.; Li, X.; Huang, R.; Chen, L.; Aime, S.; Wang, Z.; Feng, J.; Mao, Y.; Zhang, X.-Y.; Li, C. Chem. Sci. 2020, 11, 4397.

(Cheng, B.) 